DANIELE MAYUMI SinAGAWA

\title{
Uso de substâncias psicoativas por motoristas profissionais no Estado de São Paulo
}

Dissertação apresentada à Faculdade de Medicina da Universidade de São Paulo, para obtenção do título de Mestre em Ciências

Programa de Fisiopatologia Experimental Orientadora: Profa Dra Vilma Leyton

São Paulo

2015 
DANIELE MAYUMI SINAGAWA

\title{
Uso de substâncias psicoativas por motoristas profissionais no Estado de São Paulo
}

\author{
Dissertação apresentada à Faculdade de \\ Medicina da Universidade de São Paulo, para \\ obtenção do título de Mestre em Ciências \\ Programa de Fisiopatologia Experimental \\ Orientadora: Profa Dra Vilma Leyton
}

(Versão corrigida. Resolução CoPGr 6018, de 03 de outubro de 2011.

A versão original está disponível na Biblioteca FMUSP)

São Paulo

2015 
Dados Internacionais de Catalogação na Publicação (CIP)

Preparada pela Biblioteca da

Faculdade de Medicina da Universidade de São Paulo

Creprodução autorizada pelo autor

Sinagawa, Daniele Mayumi

Uso de substâncias psicoativas por motoristas profissionais no Estado de São Paulo / Daniele Mayumi Sinagawa. -- São Paulo, 2015.

Dissertação (mestrado)--Faculdade de Medicina da Universidade de São Paulo. Programa de Fisiopatologia experimental.

Orientadora: Vilma Leyton.

Descritores: 1.Anfetamina 2.Cocaína 3.Cannabis 4.Drogas ilícitas 5.Acidentes de trânsito

USP/FM/DBD-041/15 



\section{NORMALIZAÇÃO ADOTADA}

Esta dissertação está de acordo com as seguintes normas, em vigor no momento desta publicação:

Referências: adaptado de International Committee of Medical Journals Editors (Vancouver)

Universidade de São Paulo. Faculdade de Medicina. Divisão de Biblioteca e Documentação. Guia de apresentações, teses e monografias. Elaborado por Anneliese Carneiro da Cunha, Maria Julia de A. L. Freddi, Maria F. Crestanha, Marinalva de Souza Aragão, Suely Campos Cardoso, Valeria Vilhena. 3a ed. São Paulo: Divisão de Biblioteca e Documentação; 2011.

Abreviaturas dos títulos dos periódicos de acordo com List of Journals Indexed in Index Medicus. 


\section{SUMÁRIO}

\section{LISTA DE SIGLAS}

LISTA DE FIGURAS

LISTA DE TABELAS

RESUMO

\section{ABSTRACT}

1 INTRODUÇÃO

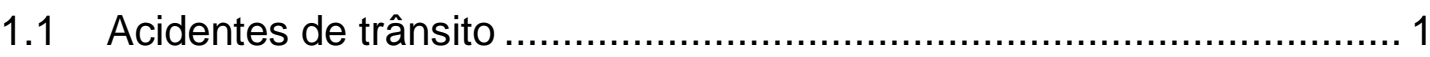

1.1.1 Definições e mortalidade ............................................................ 1

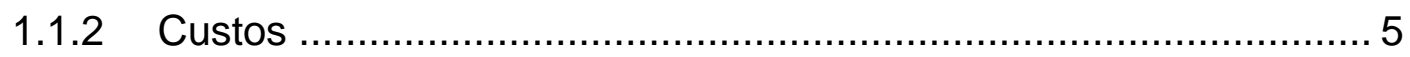

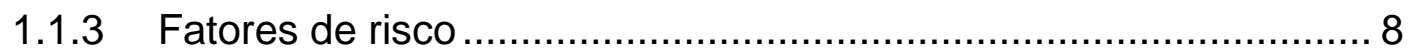

1.2 Associação entre o uso de drogas e direção ...................................... 12

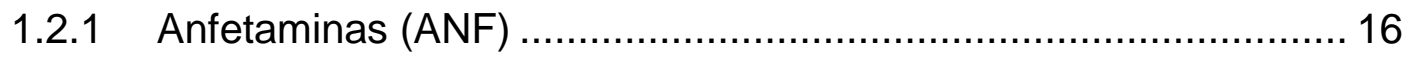

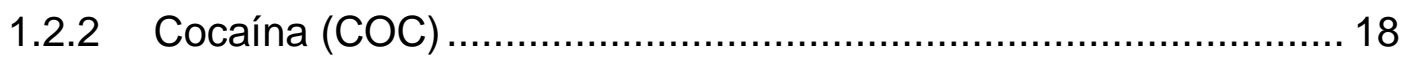

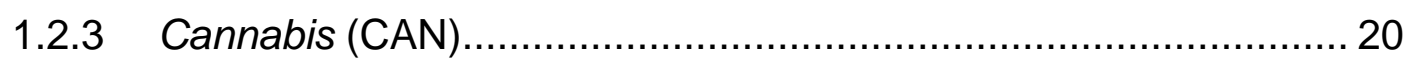

1.3 Associação entre uso de drogas e motoristas profissionais ................ 22

1.3.1 Transporte de cargas no Brasil................................................. 22

1.3.2 Aspectos laborais dos caminhoneiros e uso de drogas ................ 27

1.3.3 Prevalência do uso de drogas por caminhoneiros ........................ 28

1.4 Comandos de Saúde nas Rodovias ................................................... 34

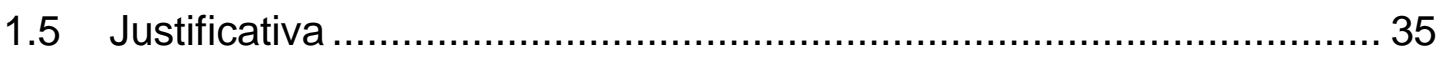

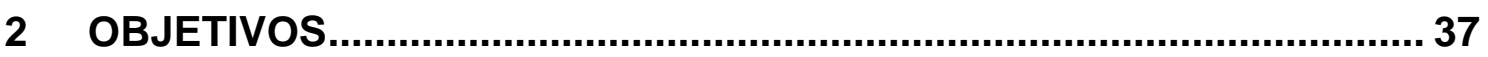

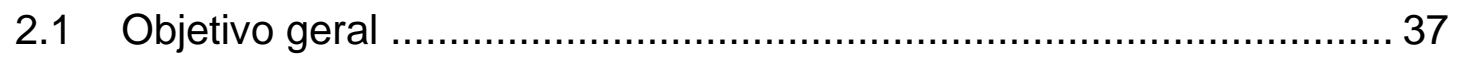

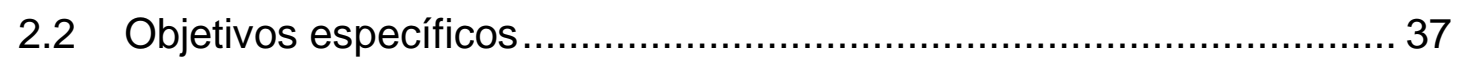

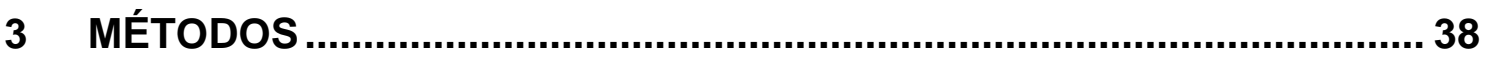

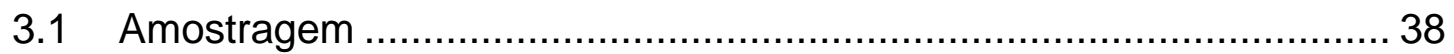

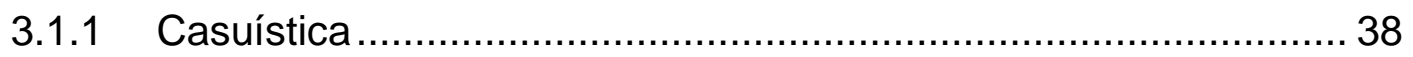

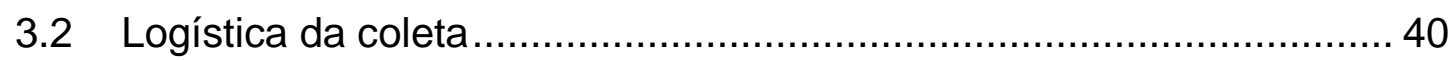

3.2.1 Abordagem dos motoristas ..................................................... 40

3.2.2 Coleta das informações ......................................................... 41 
3.2.3 Coleta das amostras biológicas ................................................. 42

3.2.4 Critérios de inclusão e exclusão ................................................ 43

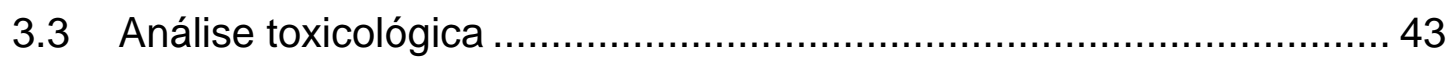

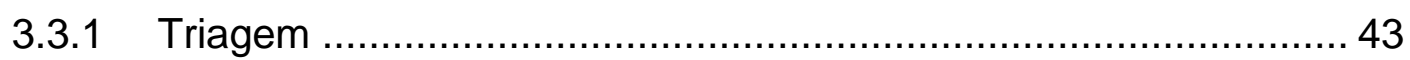

3.3.2 Confirmação ................................................................... 45

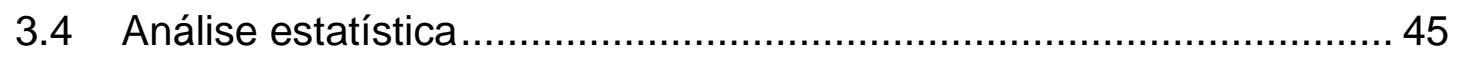

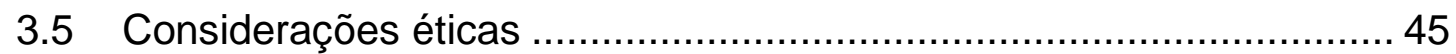

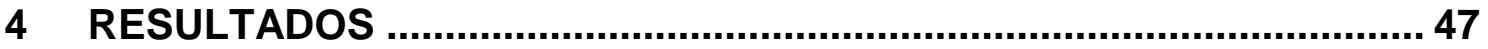

4.1 Resultado da análise toxicológica ................................................ 47

4.2 Perfil sociodemográfico dos motoristas .............................................. 51

4.3 Análises com corte no ano de 2012................................................ 52

4.3.1 Associação dos resultados das análises toxicológicas com as variáveis relacionadas ao motorista .................................................... 53

4.3.2 Associação dos resultados das análises toxicológicas com as variáveis relacionadas à viagem .................................................... 58

4.3.3 Associação do resultado da análise toxicológica com outras

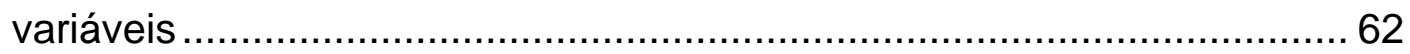

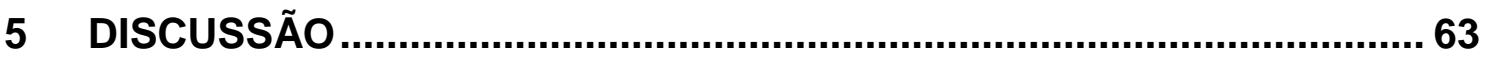

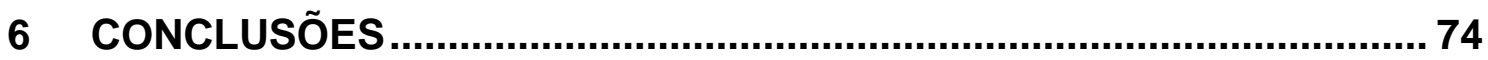

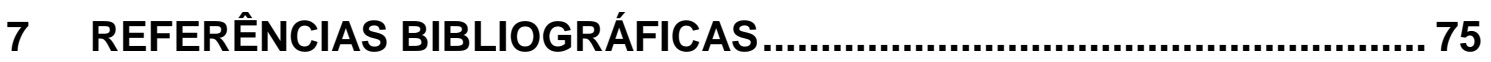

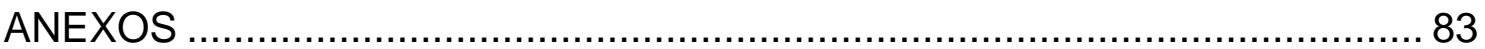




\section{LISTA DE SIGLAS}

$\Delta$-9-THC Delta-9-tetrahidrocanabinol

ANF Anfetamina

ANTP Associação Nacional de Transportes Públicos

ANVISA Agência Nacional de Vigilância Sanitária

AT Acidente(s) de trânsito

BO Boletim de ocorrência

CAPPesq Comissão de Ética para Análise de Projetos de Pesquisa

CAN Cannabis

COC Cocaína

CSR Comandos de Saúde nas Rodovias

CNS Conselho Nacional de Saúde

DCNT Doenças Crônicas Não Transmissíveis

Denatran Departamento Nacional de Trânsito

DNIT Departamento Nacional de Infraestrutura de Transportes

DPRF Departamento de Polícia Rodoviária Federal

IPEA Instituto de Pesquisa Econômica e Aplicada

LENAD Levantamento Nacional de Álcool e Drogas

MS Ministério da Saúde

OMS Organização Mundial da Saúde

PIB Produto Interno Bruto

RDC Resolução da Diretoria Colegiada 
RNTRC Registro Nacional de Transportadores Rodoviários de Cargas

SEST SENAT Serviço Social do Transporte e Serviço Nacional de Aprendizagem no Transporte

SIH Sistema de Informações Hospitalares

SNC Sistema Nervoso Central

SUS Sistema Único de Saúde

TCLE Termo de Consentimento Livre e Esclarecido

THC-COOH 11-nor- $\Delta$ 9-tetrahidrocanabinol-9-ácido carboxílico

UNODC United Nations Office on Drug and Crime

VIGITEL Vigilância de fatores de risco e proteção para doenças crônicas por inquérito telefônico 


\section{LISTA DE FIGURAS}

Figura 1 - Taxa de mortalidade por AT (por 100.000 habitantes) na União Europeia, Estados Unidos, Brasil e Noruega, entre os anos 1990 e 2010

Figura 2 - Veículos acidentados nas rodovias federais segundo o tipo de veículo, de 1957 a 2010, Brasil. FONTE: Anuário estatístico das Rodovias Federais - Acidentes de Trânsito e Ações de Enfrentamento ao Crime, DNIT, 2010

Figura 3 - Teste de imunoensaio utilizado na etapa de triagem. A amostra da foto apresentou resultado positivo para cannabis (coluna THC)

Figura 4 - Amostras de urina de caminhoneiros com resultados toxicológicos negativos $(n=1.213)$ e positivos $(n=103)$ de acordo com a droga, dentre o total de amostras coletadas $(n=1.316)$, Estado de São Paulo, 2008 a 2012 48

Figura 5 - Amostras de urina positivas de caminhoneiros distribuídas conforme $\mathrm{o}$ ano, segundo o tipo de droga $e$ percentuais relativos ao total de amostras coletadas em cada ano, Estado de São Paulo, 2008 a 2012 


\section{LISTA DE TABELAS}

Tabela 1 - Número de amostras coletadas e recusas de caminhoneiros segundo algumas características (município, rodovia e data), Estado de São Paulo, 2008 a 2012

Tabela 2 - Amostras de urina de caminhoneiros ( $\mathrm{N}$ e \%) segundo resultado toxicológico, Estado de São Paulo, 2008 a 2012

Tabela 3 - Amostras de urina de caminhoneiros ( $\mathrm{N}$ e \%) segundo resultado toxicológico de acordo com o tipo de droga, Estado de São Paulo, 2008 a 2012 49

Tabela 4 - Perfil sociodemográfico dos caminhoneiros entrevistados ( $\mathrm{N}$ e \%), Estado de São Paulo, 2008 a 2012 51

Tabela 5 - Amostras de urina positivas de caminhoneiros ( $\mathrm{Ne}$ \%) distribuídas de acordo com a droga e valores do intervalo de confiança, Estado de São Paulo, 2012 52

Tabela 6 - Amostras de urina de caminhoneiros ( $\mathrm{N}$ e \%) segundo resultado toxicológico (negativo ou positivo para anfetamina e cocaína) distribuídas de acordo com o vínculo empregatício referido, Estado de São Paulo, 2012 54

Tabela 7 - Amostras de urina de caminhoneiros ( $\mathrm{N}$ e \%) segundo resultado toxicológico (negativo ou positivo para anfetamina e cocaína) distribuídas de acordo com o tempo de serviço referido, Estado de São Paulo, 2012 
Tabela 8 - Amostras de urina de caminhoneiros ( $\mathrm{N}$ e \%) segundo resultado toxicológico (negativo ou positivo para anfetamina e cocaína) distribuídas de acordo com o número de ocupantes referido, Estado de São Paulo, 2012

Tabela 9 - Amostras de urina de caminhoneiros ( $\mathrm{N}$ e \%) segundo resultado toxicológico (negativo ou positivo para anfetamina e cocaína) distribuídas de acordo com o tipo de carga referido, Estado de São Paulo, 2012

Tabela 10 - Associações entre o consumo de drogas e as variáveis coletadas através dos relatos dos caminhoneiros, com valores de $p$ e de chi-quadrado $\left(x^{2}\right)$, Estado de São Paulo, 2012 58

Tabela 11 - Amostras de urina de caminhoneiros segundo resultado toxicológico (negativo ou positivo para anfetamina e cocaína) e associações com as variáveis relacionadas à viagem coletadas através de relatos, com valores de média, mediana, amplitude, $p$ e chi-quadrado $\left(x^{2}\right)$, Estado de São Paulo, 2012 61

Tabela 12 - Amostras de urina de caminhoneiros ( $\mathrm{N}$ e \%) segundo resultado toxicológico (negativo ou positivo para anfetamina e cocaína), distribuídas de acordo com o referido consumo ou não de álcool, Estado de São Paulo, 2012 62 


\section{RESUMO}

No mundo, os acidentes de trânsito são responsáveis pela morte de aproximadamente 1,2 milhão de pessoas, por ano. No Brasil, em 2014, foram mais de 44 mil óbitos no trânsito. O uso de substâncias psicoativas na direção é considerado um importante fator contribuinte para a ocorrência destes acidentes. Além do álcool, as drogas ilícitas mais utilizadas em nosso país são a anfetamina, a cocaína e a cannabis. As anfetaminas e a cocaína são utilizadas por motoristas de caminhão que consomem para se manterem acordados por muitas horas e estão propensos a dormir ao volante. Portanto, há necessidade de conhecer o problema para que as autoridades competentes possam implementar políticas públicas relacionadas ao uso de drogas por motoristas e assim, minimizar os acidentes de trânsito no Brasil. Objetivo: Estimar a prevalência de uso de substâncias psicoativas (anfetaminas, cocaína e cannabis) entre motoristas de caminhão que trafegavam em rodovias do Estado de São Paulo através de análise toxicológica em urina, bem como avaliar a associação do resultado toxicológico com dados sociodemográficos e ocupacionais. Métodos: Trata-se de estudo observacional do tipo transversal e a coleta dos dados foi realizada entre os anos de 2008 e 2012. Participaram do estudo 1.316 motoristas que, após assinarem o termo de consentimento livre e esclarecido e responderem um questionário sobre dados sociodemográficos e ocupacionais, forneceram uma amostra de urina. Essas amostras foram analisadas por imunoensaio e por cromatografia em fase gasosa acoplada à espectrometria de massas. Resultados: Das amostras coletadas, 7,8\% $(n=103)$ apresentaram resultado positivo para uma ou mais drogas pesquisadas e/ou seus metabólitos, dos quais 3,4\% foram resultados positivos para anfetamina, $2,8 \%$ para cocaína e 1,1\% para cannabis. O 0,5\% restante correspondeu aos casos com mais de uma droga. Com exceção do ano de 2008, as três drogas pesquisadas foram encontradas em todos os anos da pesquisa. A análise estatística mostrou que a idade e o estado civil estiveram associados com 0 uso de drogas estimulantes, enquanto o tempo de profissão, o vínculo empregatício, a etnia e a escolaridade não apresentaram associação. Em relação à viagem, estiveram associados ao consumo de drogas estimulantes a distância e o tempo de descanso noturno. $O$ descanso diurno, o tempo total e 0 viajado, as horas de direção sem descanso, o número de ocupantes e o tipo de carga não apresentaram associações significativas com o uso de drogas estimulantes. Também não houve associação estatisticamente significante entre o consumo de drogas estimulantes e doenças como hipertensão arterial, diabetes mellitus e estresse, nem com a prática de atividades físicas. Por outro lado, essa associação foi encontrada com o consumo de álcool, referido pelos caminhoneiros. Conclusão: os resultados indicam que é comum o uso de substâncias psicoativas por caminhoneiros (anfetaminas, cocaína e cannabis) e que o uso de drogas estimulantes (anfetaminas e cocaína) está associado com a idade, o estado civil, a distância percorrida e o tempo de descanso noturno.

Descritores: Anfetamina; Cocaína; Cannabis; Drogas llícitas; Acidentes de Trânsito. 


\begin{abstract}
Traffic accidents are responsible for approximately 1.2 million deaths per year worldwide. In Brazil, there were more than 44,000 traffic-related deaths in 2014. The use of psychoactive substances while driving is considered a major contributing factor to the occurrence of these accidents. In addition to alcohol, the most used illicit drugs in our country are amphetamines, cocaine and cannabis. Amphetamines and cocaine are commonly used by truck drivers to stay awake for several hours because they are likely to sleep while driving. Therefore, it is necessary to better understand this problem in order to help authorities implement public policies related to drug use by drivers and thus minimize traffic accidents in Brazil. Objective: To evaluate the prevalence of psychoactive substance (amphetamines, cocaine and cannabis) use among truck drivers in the highways of the State of Sao Paulo by toxicological analysis in urine and to associate it with sociodemographic and occupational data. Methods: This is an observational cross-sectional study in which data collection was carried out between 2008 and 2012. This study included 1,316 drivers who provided a urine sample after signing a consent form and answering to a questionnaire with sociodemographic and occupational data. The urine samples were analyzed by immunoassay and gas chromatography-mass spectrometry. Results: Of the total samples collected, $7.8 \%(n=103)$ were positive for one or more tested drugs and/or its metabolites, with $3.4 \%$ positive for amphetamine, $2.8 \%$ for cocaine and $1.1 \%$ for cannabis. The remaining $0.5 \%$ corresponded to cases with more than one drug. The three drugs were found during most of the study period, except in 2008. Statistical analysis indicated that age and marital status were associated with stimulant drug use, while the employment type, employment period, ethnicity and education were not. Concerning the travel variables, the length and night rest period were also associated with stimulant drug use. Daytime rest period, travel length period, driving time without rest, number of occupants and freight content were not associate significantly with stimulant drug use. In addition, there was no statistically significant association between consumption of stimulant drugs and diseases (such as hypertension, diabetes and stress) or physical activity. However, the association between alcohol use (reported by truck drivers) and stimulant drug use was found. Conclusion: The results indicate that the use of psychoactive substances (amphetamines, cocaine and cannabis) by truck drivers is common and the use of stimulant drugs (amphetamines and cocaine) is associated with age, marital status, travel length and night rest period.
\end{abstract}

\footnotetext{
Traffic.

Descriptors: Amphetamine; Cocaine; Cannabis; Street Drugs; Accidents,
} 


\section{INTRODUÇÃO}

\subsection{Acidentes de trânsito}

\subsubsection{Definições e mortalidade}

Um acidente de trânsito (AT) é definido como uma ocorrência fortuita ou não, da qual tenha resultado ferimento, dano, estrago, avaria ou ruína. Essa ocorrência acidental possui o envolvimento, em proporções variáveis, do homem, do veículo, da via e dos demais elementos circunstanciais ${ }^{1}$.

As definições do Ministério da Saúde (MS) diferenciam os acidentes de transporte e AT da seguinte maneira: o primeiro, configura-se como todo acidente que envolva um veículo usado para o transporte de pessoas ou de mercadorias de um local para outro; já os AT são os que ocorrem especificamente na via pública, que é definida como o espaço para a circulação de pessoas ou de bens de um lugar para outro. A pista é a parte da via pública que é preparada, conservada e habitualmente usada para o trânsito de veículos. Dessa maneira, para considerar como AT, devem-se excluir do total dos acidentes de transporte, os acidentes por água e os acidentes de transporte aéreo ou espacial ${ }^{2}$.

As lesões e mortes decorrentes desses AT estão classificadas dentre as causas externas de morbidade e mortalidade, que incluem outros acidentes (afogamento, envenenamento, quedas ou queimaduras) e também os eventos 
de violência (agressões/homicídios, suicídios, tentativas de suicídio, abusos físicos, sexuais e psicológicos) $)^{3}$.

As causas externas também podem ser classificadas de acordo com a intencionalidade do evento: existem as lesões intencionais (homicídios, suicídios, envenenamentos premeditados e intervenções legais) e as lesões não-intencionais ou acidentais (acidentes de transporte, afogamentos, quedas, queimaduras e intoxicações acidentais). Assim, os AT são caracterizados como eventos não-intencionais, que envolvem pelo menos um veículo, motorizado ou não, que circula por uma via para o trânsito de veículos ${ }^{4}$.

No mundo, segundo o relatório de 2013 da Organização Mundial da Saúde (OMS), os AT são responsáveis pela morte de aproximadamente 1,24 milhão de pessoas (3.397/dia) e de 20 a 50 milhões de vítimas não-fatais, por ano. Atualmente, os AT constituem-se como a oitava causa de morte em todo o mundo e a primeira causa entre os jovens de 15 a 29 anos. O mesmo relatório descreve que a tendência é que, em 2030, os AT ocupem a quinta posição no ranking das causas de morte (com 2,4 milhões de vítimas) ${ }^{5}$.

No Brasil, as causas externas constituem a terceira causa de mortalidade (superada apenas pelas neoplasias e doenças do aparelho circulatório) ${ }^{6}$ e passam a ocupar a primeira posição quando se restringe a análise ao grupo de pessoas de 1 a 39 anos $^{3}$. O crescimento de mortes por causas externas na população brasileira ocorreu principalmente a partir da década de 80 , quando estas passaram a ocupar a segunda posição dentre os óbitos em geral. No ano 2000, ocorreram 118.367 mortes por essas causas, o que representou $12,5 \%$ do total de óbitos? 
Dentre as mortes por causas externas, os AT ocupam a segunda colocação (homicídios em primeiro lugar), respondendo por $26,5 \%$ do total de vítimas. Isso corresponde a mais de 44 mil óbitos anualmente no trânsito ${ }^{8,9}$.

Para traçar o panorama dos AT no Brasil, deve-se considerar não somente os números atuais, mas também a evolução histórica desses índices. O período entre 1996 e 2010 apresentou um crescimento preocupante no número de óbitos por AT, especialmente a partir do ano 2000. Passou a ser ainda pior na década de 2000 a 2011, quando o número de mortes nas vias públicas passou de 28.995 para 43.256 , o que representou um incremento de 49,2\% em 11 anos. As taxas de mortalidade no trânsito por número de habitantes, considerando o aumento da população, cresceram em $25,8 \%{ }^{10,11}$. Em 2010, essa taxa foi de 19,6 por 100 mil habitantes ${ }^{3}$.

O aumento da violência no trânsito não ocorreu apenas no Brasil, mas também em outros países. A estimativa da OMS é que $90 \%$ das mortes por AT aconteçam em países de média e baixa renda que, em conjunto, possuem menos da metade dos veículos do mundo. Nos últimos anos, esses países apresentaram as maiores taxas de mortalidade no trânsito devido a um rápido crescimento no número de veículos sem que houvesse investimentos em estratégias de segurança viária ${ }^{5,10}$. No período entre 2007 a 2010, enquanto 88 países, em sua maioria, países desenvolvidos conseguiram reduzir o número de vítimas fatais, outros 87 países de baixa e média renda tiveram aumentos significativos na mortalidade por $\mathrm{AT}^{5}$.

Em relação à mortalidade ao longo dos últimos anos, ao comparar o Brasil com países desenvolvidos - como Estados Unidos ou países da União Europeia - podemos observar que enquanto esses países diminuíram as taxas, 
o Brasil apresentou crescimento contínuo desde $2000^{12}$, conforme mostra a Figura 1.

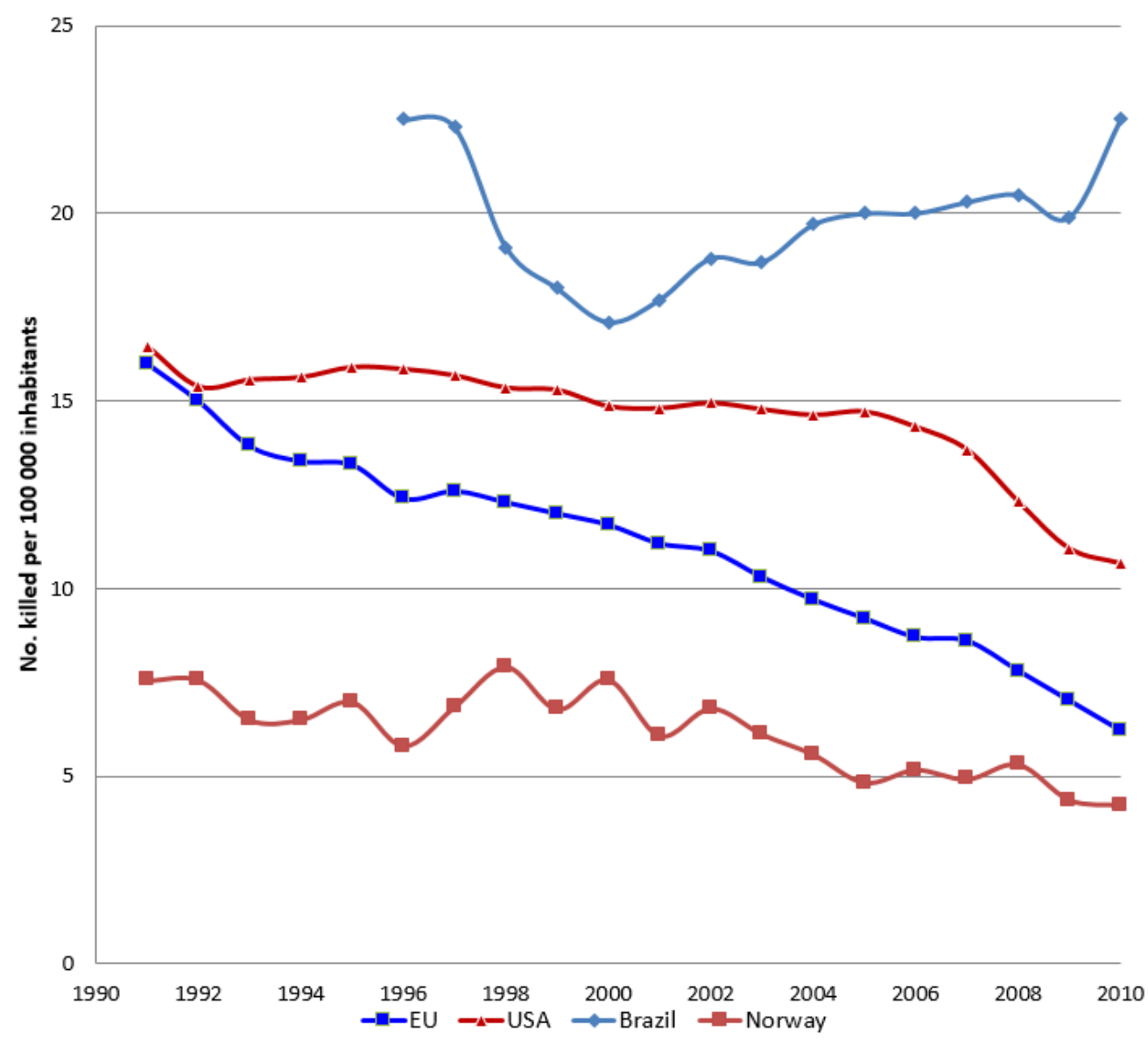

Figura 1 - Taxa de mortalidade por AT (por 100.000 habitantes) na União Europeia, Estados Unidos, Brasil e Noruega, entre os anos 1990 e 2010*.

A problemática dos AT é um assunto muito antigo e bastante discutido mundialmente; por exemplo, já no ano de 1955, em um evento em Genebra, Suíça, denominado "Assembleia Mundial da Saúde", foi proposto que a luta contra os AT fosse considerada um problema de saúde pública. Anos depois, em 1961, a OMS promulgou como o tema do ano "Acidentes e sua prevenção". 
O grande objetivo do evento era chamar a atenção dos governos e da população para o número crescente de AT, destacando a falta de medidas preventivas e a necessidade urgente de alguma ação de combate a esses acontecimentos. Há 20 anos, Mello Jorge e Latorre, em 1994, já afirmavam que, mesmo passados 30 anos deste evento, os objetivos continuavam atuais e relevantes, uma vez que os números continuavam elevados e crescentes, com a inexistência ainda, das medidas preventivas referidas ${ }^{13}$.

Frente aos elevados números de AT no mundo, em março de 2010, com base em estudos da OMS, a Assembleia Geral das Nações Unidas estabeleceu a década 2011 a 2020 como a "Década de Ação para Segurança Viária", cujo objetivo é estabilizar e posteriormente, reduzir a tendência de crescimento de mortes por AT, salvando um estimado de 5 milhões de vidas no período. Para tal, a iniciativa propõe a formulação e implementação de planos nacionais, regionais e mundial 5 .

\subsubsection{Custos}

Em todo o mundo, anualmente, estima-se que as causas externas sejam responsáveis por mais de 5 milhões de mortes e que, para cada morte, ocorram dezenas de hospitalizações, centenas de atendimentos de emergência e milhares de consultas ambulatoriais decorrentes desses eventos. No Brasil, só em 2010, foram autorizadas 929.893 internações hospitalares por causas externas nos serviços financiados pelo Sistema Único de Saúde (SUS)³.

Ao comparar as internações devido a causas naturais e causas externas, as últimas representaram menos de $10 \%$ do total de internações no ano de 
2000, tiveram tempo menor de permanência no hospital e gastaram cerca de $10 \%$ do valor total pago para todas as internações. Embora a permanência seja menor, os gastos do SUS medidos pelo custo-dia $(47,4 \%)$ e gasto médio (19\%), foram superiores aos das internações por causas naturais. As causas mais frequentes de internação por causas externas foram quedas e $\mathrm{AT}^{7}$.

Analisando-se o perfil da morbidade hospitalar segundo tipos de causas externas, especificamente as lesões decorrentes de AT corresponderam a $15,7 \%$ das hospitalizações no âmbito do SUS em $2011^{3}$. Segundo dados do Sistema de Informações Hospitalares (SIH) do Ministério da Saúde, as 159.327 internações hospitalares por AT custaram aos cofres públicos um total de $\mathrm{R} \$$ 210,8 milhões em $2011^{11}$. No mundo, esses acidentes já representam um custo global de US\$ 518 bilhões ao $a n 0^{10}$. A problemática se agrava nos países de baixa e média renda, nos quais as famílias economicamente prejudicadas são atingidas por exorbitantes custos médicos e gastos indiretos em decorrência dos AT. Estima-se que anualmente 1 a $2 \%$ do produto interno bruto (PIB) desses países sejam destinados a esses custos 5 .

Além dos custos médicos hospitalares existem diversos outros custos originados pelos AT que devem ser incorporados para o cálculo dos gastos reais desses acidentes como as perdas materiais, os danos veiculares, os custos previdenciários, entre outros ${ }^{11}$. Ademais, as lesões decorrentes dos AT afetam toda a vida das vítimas, com sequelas permanentes, o que gera a incapacidade para o trabalho ou outras funções cotidianas, faltas ao trabalho, gastos com o pagamento de pensões e tratamentos de saúde ${ }^{3}$. 
Os dados destes custos secundários acima descritos foram estudados e organizados em relatórios executivos, que foram realizados pelo Instituto de Pesquisa Econômica e Aplicada (IPEA), publicados nos anos de 2003 e 2006. Foram considerados todos os gastos cabíveis relacionados com os AT (como os custos associados às pessoas, aos veículos, à via e os custos institucionais) no período do acidente e posterior a ele $\mathrm{e}^{14,15}$.

O primeiro relatório do IPEA $^{14}$ realizado com a Associação Nacional de Transportes Públicos (ANTP), nos anos entre 2001 e 2003 mostrou que os AT em áreas urbanas corresponderam a uma perda de $R \$ 5,3$ bilhões no ano, sendo de $R \$ 144,5$ mil o custo médio unitário para os acidentes com morte. $\mathrm{Na}$ época, considerou-se que este valor aumentaria consideravelmente caso fossem incluídos os custos dos acidentes rodoviários. Por este motivo, em 2006, o IPEA e o Departamento Nacional de Trânsito (DENATRAN) realizaram novo estudo ${ }^{15}$ sobre os custos dos AT, desta vez focado nas rodovias brasileiras e o valor estimado foi de $\mathrm{R} \$ 22$ bilhões com base nos números de AT do ano de 2005.

A partir dos dois levantamentos descritos, em 2013, o sociólogo Waisefilsz ${ }^{11}$ realizou uma nova estimativa de custos. Primeiro, adaptou os gastos indexando os valores monetários, uma vez que as cifras dos custos disponíveis eram de anos anteriores. Em seguida, avaliou o índice de crescimento na quantidade de AT dos últimos anos e atualizou os cálculos do custo considerando o número atual de acidentes. O valor final estimado foi de $\mathrm{R} \$ 44,6$ bilhões, somente para o ano de 2011. 
Apesar dos estudos que consideram os consequentes custos dos AT, o número de sequelas deixadas nas vítimas ainda não é conhecido no país. Um primeiro ensaio sobre o tema foi realizado em um trabalho de $2012^{16}$ que propôs explorar os dados e fazer uma aproximação do número de sequelas deixadas pelos AT e estabelecer cruzamentos entre os acidentes e as lesões. O estudo teve como fonte o SIH do Ministério da Saúde e coletou o número de internações do ano de 2008. Os resultados mostraram que 3\% dos pacientes atendidos e que tiveram alta, apresentaram uma sequela. Os dados revelaram um quadro preocupante, visto que, pacientes sequelados podem vir a ser portadores de incapacidades e deficiências e certamente sofrem com as mudanças e repercussões pessoais, familiares, ocupacionais e financeiras que tal fato representa.

\subsubsection{Fatores de risco}

Os AT muitas vezes são apresentados de forma errônea como fatos casuais, acaso ou preço do progresso e, dessa maneira, constrói-se uma imagem de fatalidade em torno de um problema que foge do controle e da responsabilidade das instituições humanas, já a partir da própria nomenclatura. Portanto, deve-se tentar desconstruir essa imagem prevalente na opinião pública, na mídia e, principalmente, nas instituições públicas responsáveis pela gestão do trânsito e da mobilidade territorial ${ }^{11}$.

Apesar da denominação 'acidente' ser utilizada para descrever eventualidades ou imprevistos, a ocorrência do evento acidental é de caráter totalmente evitável, por mais que ocorra de modo não-intencional. Para o 
estudo dos AT, uma vez considerados como um evento evitável, deve-se então investigar as causas que levam ao seu acontecimento. Segundo classificação do Departamento Nacional de Infraestrutura de Transportes (DNIT) ${ }^{17}$, as causas dos AT são usualmente agrupadas em três categorias de fatores de risco: fatores humanos; fatores ligados à infra-estrutura e ao meio-ambiente; fatores ligados aos veículos.

A complexidade na redução dos AT se deve justamente ao fato de que eles são causados por um conjunto de circunstâncias e fatores relacionados ao usuário, ao veículo e à via pública. Por isso, para uma prevenção eficaz, há necessidade de concentrar esforços por todas as áreas atuantes no setor: engenheiros ligados à indústria automobilística e ao transporte; médicos das áreas preventiva e curativa; educadores; policiais, entre outros. Desta forma, somando-se às melhorias das vias, um desenho seguro dos veículos e uma educação adequada dos condutores, poder-se-iam amenizar os fatores de risco para a ocorrência dos $\mathrm{AT}^{13}$.

Conhecer as vítimas do ponto de vista de suas características epidemiológicas é importante porque pode detectar quem é vulnerável, em que grau e por que motivos, como e quando os acidentes acontecem e, principalmente, quais são eles, para, assim, combatê-los e preveni-los ${ }^{16}$.

É importante que se analisem as variáveis dos acidentes já ocorridos (onde se concentraram, onde aconteceram os mais graves, quais foram as suas causas) a fim de se identificar os fatores de risco que contribuíram para seu acontecimento. Para tal, o DNIT emitiu um relatório em $2008^{17}$ com dados de boletins de ocorrência $(\mathrm{BO})$ de acidentes rodoviários (ocorridos em sete 
rodovias federais catarinenses) entre os anos de 2005 a 2007. As informações foram: tipo de colisão; condições do tempo e do pavimento; características das pessoas envolvidas, entre outros. Os números indicaram que, em quase sua totalidade, os AT aconteceram devido à negligência do condutor (falta de atenção ou velocidade incompatível), corroborando a hipótese de que o fator humano é o principal responsável pela ocorrência desses acidentes. O relatório mostrou que os acidentes mais comuns foram as colisões traseira e lateral e a via apresentava-se em boas condições de conservação, não sendo, portanto, responsável pela ocorrência destes AT.

Embora o sono também seja um fator de risco importante na causa de AT, ainda é pouco estudado principalmente pela dificuldade de se pesquisar essa variável após a ocorrência de um acidente. A tendência a adormecer é aumentada pela privação e pela interrupção do sono, sendo o efeito dessa perda cumulativo. O sub-registro da sonolência existe por diversos motivos, por exemplo: os envolvidos não desejam referir aos policiais, nem aos amigos ou familiares, que eles dormiram na direção porque isso significa admitir responsabilidade pelo acidente. A sonolência é, muitas vezes, ignorada por falta de reconhecimento do motorista, que atribui o acidente a outras causas como a má condição climática ou o estado insuficiente de preservação da rodovia $^{18}$.

Há 30 anos, em 1984, a OMS realizou um evento que ficou conhecido como Conferência de Roma, no qual foram discutidas as causas dos AT. A partir de provas procedentes de países desenvolvidos, baseadas em análises detalhadas de acidentes, concluiu-se que a conduta dos motoristas era 0 
principal fator que contribuía para a ocorrência da maioria dos AT. Além disso, o relatório desta Conferência mostrou que o problema do condutor que bebe e consome drogas é universal. A respeito do álcool foi afirmado que, na época, já haviam provas científicas bem fundamentadas e amplamente aceitas de sua influência negativa sobre a aptidão para conduzir e no aumento do risco de acidentes, assim como a gravidade de suas consequências. As conclusões de estudos em vários países já mostravam que o álcool era a causa direta de 30 a $50 \%$ dos AT graves. Porém, a respeito da influência e dos efeitos das drogas na direção (usadas isoladas ou associadas ao álcool) foi constatado que existiam poucos dados acerca da magnitude do problema. Era conhecido apenas o consumo de estimulantes em alguns países, sobretudo entre caminhoneiros que percorriam grandes distâncias e trabalhavam durante muitas horas. Dessa maneira, devido à falta de informações mais aprofundadas sobre o tema, concluiu-se que era necessário estudar mais a participação das substâncias psicoativas em $A T^{19}$.

Embora já seja reconhecida a associação entre uso de drogas e álcool e o aumento de acidentalidade no trânsito e na violência em geral no mundo e ainda que existam tentativas de se realizar programas educativos de prevenção pelo governo e algumas entidades, não existem números oficiais que mostrem a real gravidade do problema no Brasil.

Considerando essa hipótese que o fator humano é o principal causador dos AT, devemos então estudar, de modo aprofundado, os fatores de risco relacionados especificamente ao condutor. 
Tendo em vista que os AT são considerados uma causa evitável de morte, o uso de álcool e outras drogas por motoristas deve ser tratado como um problema de saúde de alta prioridade no Brasil ${ }^{20}$.

Em relação ao consumo de álcool pela população brasileira, em 2013, o projeto VIGITEL ${ }^{21}$ (Vigilância de fatores de risco e proteção para doenças crônicas por inquérito telefônico) fez uma estimativa sobre frequência e distribuição sociodemográfica de fatores de risco e proteção para doenças crônicas não transmissíveis (DCNT) nas capitais dos 26 estados brasileiros e no Distrito Federal e avaliou também o uso de bebidas alcoólicas. O resultado mostrou que a frequência de consumo de bebidas alcoólicas nos últimos 30 dias tinha sido de $16,4 \%$ da população pesquisada. $O$ inquérito também estimou a frequência de indivíduos que referiram conduzir veículo motorizado após o consumo de bebida alcoólica, independentemente da quantidade de bebida consumida e da periodicidade dessa prática. Do total de entrevistados, $5,2 \%$ dos indivíduos referiram conduzir veículo motorizado após consumo de bebida alcoólica, sendo essa proporção bem maior em homens $(9,4 \%)$ do que em mulheres $(1,6 \%)$.

Já em relação ao consumo de drogas e direção, os estudos que fazem referência a este tema são compilados a seguir.

\subsection{Associação entre o uso de drogas e direção}

O consumo de substâncias psicoativas é considerado uma questão de saúde pública extremamente relevante em praticamente todo o mundo ${ }^{22}$. Segundo estimativa de 2014 da United Nations Office on Drug and Crime 
$(\mathrm{UNODC})^{23}$, entre 3,5 e $7 \%$ da população mundial de idade entre 15 a 64 anos (o equivalente a aproximadamente 162 a 324 milhões de pessoas), haviam feito uso de alguma substância psicoativa nos últimos 12 meses anteriores à pesquisa realizada.

Também no Brasil, as informações a respeito do uso de drogas indicam números preocupantes. As condições socioculturais existentes, a vasta extensão territorial e a localização próxima a países produtores de drogas são fatores que contribuem para essa situação. Na sociedade em geral, também segundo estimativa da UNODC ${ }^{24}$, que traz dados dos anos de 2000 e 2001, 6,3\% da população brasileira com mais de 15 anos (o equivalente a aproximadamente 10 milhões de pessoas) usam regularmente alguma substância ilícita, sendo 5,8\% cannabis, 0,8\% cocaína e 0,7\% anfetaminas.

Em 2007, Carlini et al. ${ }^{25}$ atualizaram os números e relataram que $22,8 \%$ da população acima de 12 anos de idade já fizeram uso ilícito e experimental de pelo menos uma substância psicoativa, o que corresponde a quase 12 milhões de pessoas.

Números mais recentes estão descritos no relatório final do "II Levantamento Nacional de Álcool e Drogas" (LENAD) ${ }^{26}$ realizado em 2012, que foi um estudo populacional sobre os padrões de uso de álcool, tabaco e drogas ilícitas na população brasileira com mais de 14 anos ( $n=4.607$ entrevistados). Os resultados mostraram que a substância ilícita com maior prevalência de uso na população brasileira é a cannabis. Do total da população adulta, 6,8\% (ou seja, uma projeção de 7,8 milhões de pessoas) declarou já ter feito uso de cannabis alguma vez na vida. A prevalência do uso de cocaína foi de 3,8\%, 
enquanto os estimulantes (assim referido pelo relatório, as drogas não foram especificadas) tiveram uma prevalência de uso de 1,3\%.

Dirigir é uma tarefa complexa, pois o condutor recebe informações continuamente e deve analisá-las e reagir a respeito destas. As substâncias que influenciam nos processos cerebrais relacionados à direção, certamente afetarão seu desempenho na condução de veículos ${ }^{27}$. Segundo Gates et al. $(2013)^{28}$, os motoristas que consomem substâncias psicoativas estão mais propensos a assumir comportamento de risco e realizar atos que aumentam a probabilidade de ocorrência de AT, por exemplo, dirigir acima da velocidade permitida ou ultrapassar sinal vermelho.

O uso de substâncias psicoativas altera a percepção dos motoristas e afeta direta e negativamente na condução. Portanto, o uso dessas substâncias pode estar relacionado com a ocorrência de AT e ser considerado como um fator de risco para esses eventos. Em 2003, Drummer et al. ${ }^{29}$ afirmaram que as drogas lícitas (álcool), medicinais (tranquilizantes e antidepressivos) e ilícitas (anfetamina, cocaína e cannabis,) têm expressiva participação na ocorrência de AT, geralmente com vítimas fatais. Drummer et al. (2007) ${ }^{30}$ relataram que os motoristas que haviam feito uso de substâncias psicoativas tornavam-se mais prováveis de serem culpados por colisões do que outros condutores que não haviam utilizado drogas.

No Brasil, em 2010, foi realizado um estudo nas 27 capitais brasileiras com o objetivo de estimar a prevalência do uso de álcool e outras drogas por motoristas, tanto profissionais como particulares. Foram coletadas amostras de 
fluido oral de 3.398 motoristas e os resultados mostraram que $4,6 \% \quad(n=150)$ dos condutores haviam consumido algum tipo de droga, assim discriminadas: cocaína $(2,1 \%)$, cannabis $(1,5 \%)$, anfetamínicos $(1,2 \%)$ e benzodiazepínicos $(1 \%)^{31}$.

Ao dirigir sob a influência de álcool, o condutor tem probabilidade aumentada de envolver-se em AT, fato comprovado pelas diretrizes médicas elaboradas a partir de evidências científicas. Porém, com relação à participação de outras drogas nos acidentes, o tema ainda é pouco abordado, pouco analisado e precariamente divulgado no Brasil, portanto, existe a necessidade de pesquisas que identifiquem a prevalência de uso dessas substâncias entre os condutores no trânsito brasileiro para quantificar a extensão do problema e a subsequente adoção de medidas educativas e repressivas para seu controle efetivo ${ }^{32}$.

Os efeitos das drogas no desempenho dos motoristas já são bem conhecidos no mundo e vários são os estudos sobre a prevalência do uso de drogas por motoristas que foram mortos e feridos em AT. Entretanto, no Brasil, a participação das drogas nos AT ainda é pouco conhecida e divulgada ${ }^{27}$.

De acordo com os objetivos do presente trabalho e de acordo com as drogas mais utilizadas pelos brasileiros segundo a literatura, a seguir serão listados os principais aspectos e efeitos na direção dos três seguintes grupos de drogas: anfetaminas, cocaína e cannabis. 


\subsubsection{Anfetaminas (ANF)}

As anfetaminas são substâncias sintéticas estimuladoras do Sistema Nervoso Central (SNC). Apesar de produzirem inicialmente euforia, bem-estar, aumento da capacidade física e intelectual, também podem provocar irritação, insônia, nervosismo e inquietação. Às vezes, em indivíduos hipersensíveis, produzem alucinações, delírios e até mesmo convulsões. Depois da fase inicial euforizante, é comum o aparecimento de uma fase secundária depressiva com fadiga, torpor, sonolência e inibição mental ${ }^{33}$.

Os sintomas sugestivos de intoxicação por anfetaminas incluem aumento da pressão arterial, taquicardia, dilatação pupilar, hiperreflexia, anorexia, sudorese, calafrios, náusea ou vômito e comportamentos anormais, tais como hipervigilância, agressividade, grandiosidade, agitação e perturbação do juízo crítico. Em raros casos pode-se desenvolver um delirium a menos de 24 horas da ingestão. O uso crônico pode induzir alterações da personalidade e do comportamento e a interrupção da ingestão após uso prolongado ou intenso pode produzir uma reação de abstinência ${ }^{22}$.

São conhecidas como "bolinha" por estudantes que passam noites inteiras estudando ou por pessoas que fazem regimes de emagrecimento. Nas estradas são popularmente denominadas "rebites" e são utilizadas por motoristas que dirigem durante várias horas seguidas sem descanso, a fim de cumprir prazos pré-determinados, segundo relatos na mídia.

No Brasil, as anfetaminas eram comercializadas como medicamentos moderadores do apetite para tratamento da obesidade e para indivíduos que sofrem de transtornos psicológicos. Eram medicamentos controlados que 
necessitavam de receita médica para serem adquiridos ${ }^{22,34}$, porém eram facilmente adquiridas em postos de gasolina nas rodovias do país, apresentando baixos custos e sem controle ${ }^{39}$. Atualmente, a comercialização está legalmente proibida, desde outubro de 2011. Na referida data, entrou em vigor a Resolução da Diretoria Colegiada (RDC) № 52, de 06 de outubro de 2011, da Agência Nacional de Vigilância Sanitária (ANVISA) ${ }^{40}$, na qual se determinou a proibição da fabricação, importação, exportação, distribuição, manipulação, prescrição, dispensação, aviamento, comércio e uso de medicamentos ou fórmulas medicamentosas que contenham anfepramona, femproporex e mazindol, assim como seus sais, isômeros e intermediários.

O uso indiscriminado desses medicamentos pode levar à dependência. Além disso, são contraindicados a pacientes com hipertensão, problemas cardiovasculares, hipertireoidismo e glaucoma e ainda por indivíduos com história de abuso de medicamentos e mulheres em gestação ${ }^{35}$.

As anfetaminas estimulam as funções cognitivas e psicomotoras e podem aumentar perigosamente a autoconfiança do motorista, resultando na maior probabilidade de envolvimento em situações de risco no trânsito. O usuário se torna agressivo no início e apático quando os efeitos agudos passam ${ }^{36}$.

Testes realizados em simulador de direção levaram à conclusão de que os efeitos agudos da anfetamina prejudicam o desempenho do motorista, quando passa a não sinalizar corretamente as manobras que pretende executar e as realiza em tempo superior ao necessário à tomada de decisões, deixando de parar em semáforo vermelho e reagindo com mais lentidão às habilidades exigidas para uma condução segura ${ }^{37}$. Uma pesquisa feita em 
2012, também utilizando testes em simulador, mostrou que, após 3 horas do uso de metanfetamina, os voluntários apresentaram direção veicular insegura, produzindo mais violações do limite de velocidade, deixando de sinalizar manobras como mudança de faixa e mantendo acionada a seta de direção após ingressar na via ${ }^{38}$.

No Brasil, motoristas de caminhão relatam que para suportar as exaustivas jornadas de trabalho a que estão submetidos, fazem uso de anfetaminas, como o femproporex e a anfepramona, indicados para o controle da obesidade. $O$ consumo desses estimulantes tem sido associado a problemas de saúde e com a ocorrência de acidentes de trânsito ${ }^{31}$.

\subsubsection{Cocaína (COC)}

A cocaína é um potente estimulante do SNC usado sem indicação terapêutica para produzir euforia ${ }^{22}$. É um alcaloide obtido das folhas da Erytroxylon coca, planta originária da Bolívia e do Peru ${ }^{41}$. Devido à sua forte ação vasoconstritora que auxilia a reduzir hemorragias locais, o hidrocloreto de cocaína era comumente utilizado como anestésico local em odontologia, oftalmologia e cirurgias de ouvido, nariz e garganta ${ }^{22}$.

Seu uso repetido produz dependência. É uma droga geralmente vendida sob a forma de um pó, o cloridrato de cocaína, utilizada principalmente pela via intranasal e assim que é aspirado produz efeitos imediatos (entre 1 a 3 minutos de latência), que duram em torno de 30 minutos. A cocaína vendida nesta forma é frequentemente adulterada com açúcares ou anestésicos locais ${ }^{22,41}$. 
A cocaína também pode ser ingerida oralmente, geralmente com álcool; os usuários de opióides e cocaína combinados geralmente os injetam por via intravenosa. Outra forma utilizada por usuários é a forma de base: o crack, que é pouco solúvel em água mas que se volatiliza quando aquecido e portanto, é fumado. $O$ efeito aparece de 4 a 6 segundos após a inalação e pode durar em torno de 5 a 7 minutos. Os sintomas podem ser: fala acelerada e desconexa, sentimento de exaltação, aumento da confiança e autoestima, perturbação do juízo crítico e o usuário tende a cometer atos irresponsáveis, o que pode levar ao acontecimento de $A T^{22,41,42}$.

Inicialmente, a cocaína pode levar a uma pequena melhora no desempenho do motorista logo após o início de sua ação farmacológica, na fase de euforia. No entanto, o condutor estará mais propenso a assumir comportamentos de risco, o que pode levar ao maior envolvimento em AT. O prejuízo observado no desempenho pode ocorrer em razão da perda de concentração e atenção e maior sensibilidade à luz em virtude das pupilas dilatadas. Alterações mentais decorrentes dos efeitos psicoativos tais como nervosismo, irritabilidade, agressividade, paranoia e alucinações podem influenciar negativamente o comportamento na condução de veículos. O uso de cocaína está associado à condução em excesso de velocidade, perda do controle do veículo, colisões, direção agressiva e desatenta, com execução de manobras de alto risco ${ }^{36}$.

Em 2012, Stoduto et al. ${ }^{43}$ afirmaram que a cocaína é uma das drogas ilícitas mais encontradas entre motoristas acidentados. Os autores realizaram uma pesquisa no Canadá entre os anos de 2002 a 2008 e através de relatos de 7.284 motoristas identificaram que usuários de cocaína possuíam chance de 
$18,7 \%$ de se envolver em colisões enquanto entre os não usuários a chance era de apenas $7,4 \%$.

\subsubsection{Cannabis (CAN)}

A planta Cannabis sativa, conhecida popularmente como maconha, contém pelo menos 60 canabinóides, muitos dos quais biologicamente ativos. O principal constituinte ativo é o delta 9-tetrahidrocanabinol ( $\triangle-9-\mathrm{THC}$ ou THC), que é o responsável pelos efeitos farmacológicos da planta ${ }^{22}$. A via de administração mais utilizada é a inalatória que é mais efetiva em relação à absorção do $\Delta-9-$ THC, mas também pode ser ingerido ${ }^{41}$.

O pico de intoxicação após fumada é alcançado entre 15 a 30 minutos e os efeitos duram de duas a seis horas. Os canabinóides permanecem no corpo por longos períodos e acumulam-se após uso contínuo, podendo ser encontrados na urina por dois ou três dias após o indivíduo fumar um único cigarro ou até seis semanas após o último uso em usuários crônicos ${ }^{41}$.

A intoxicação pela cannabis produz sensação de euforia, leveza dos membros e geralmente retração social. Prejudica a capacidade para dirigir veículos, pois prejudica a memória imediata, o nível de atenção, o tempo de reação, a capacidade de aprendizado, a coordenação motora, a percepção de profundidade, a visão periférica, a percepção do tempo e a detecção de sinais. Outros sinais de intoxicação podem incluir ansiedade excessiva, desconfiança ou ideias paranoides em alguns e euforia ou apatia em outros, juízo crítico prejudicado, irritação conjuntival, aumento de apetite, boca seca e taquicardia ${ }^{22}$. 
Uma vez que a cannabis altera o desempenho cognitivo e psicomotor dos motoristas, o condutor tem prejuízo da coordenação, da atenção dividida, das funções visuais, do tempo de reação e, consequentemente, da capacidade para dirigir com segurança. Os efeitos nocivos concentram-se nas primeiras duas horas e diminuem consideravelmente ao longo da terceira e quarta horas. O declínio no desempenho do motorista pode chegar a atingir $70 \%$ a $80 \%$ com níveis elevados de consumo ${ }^{44}$.

Uma revisão sistemática da literatura levou à conclusão de que o consumo de cannabis praticamente duplica o risco de motoristas provocarem acidentes, principalmente colisões graves ou fatais ${ }^{45}$. Os autores relataram risco 1,9 vezes maior de provocar acidentes para condutores que consomem cannabis mais de 50 vezes ao ano.

Motoristas envolvidos em colisões fatais no trânsito, que apresentavam $\Delta$ 9-THC no sangue, tinham probabilidade 2,7 vezes maior de serem responsáveis pelo acidente, alcançando probabilidade 6,6 vezes maior quando a dose era igual ou superior a $5 \mathrm{ng} / \mathrm{mL}$ de sangue ${ }^{46}$. 


\subsection{Associação entre uso de drogas e motoristas profissionais}

\subsubsection{Transporte de cargas no Brasil}

O Brasil é um país extenso e possui uma malha rodoviária de aproximadamente 1,7 milhão de quilômetros, dos quais apenas $12 \%$ são pavimentados. As estradas não pavimentadas correspondem a $80 \%$ do total e os $8 \%$ restantes são estradas ainda somente planejadas. A Região Sudeste isolada concentra mais de 500 mil quilômetros de rodovias, o que corresponde a um terço do total, demonstrando a importância da região dentro do cenário nacional de deslocamento rodoviário ${ }^{47}$. Porém, como consequência da grande circulação de veículos, a Região Sudeste também concentra um terço do total do número de AT do país ${ }^{48}$.

O número de AT registrado nas rodovias federais em 2010 foi de 182.900, ocasionando mais de 8 mil mortos e 102 mil feridos. Dos quase 320 mil veículos que se envolveram nestes AT, quase 25\% (80 mil) eram veículos de carga 49

A Figura 2 mostra que os acidentes que envolveram os veículos de carga (1957-2010) ${ }^{1}$ representam uma alta proporção do total de AT em rodovias federais, apresentando números abaixo dos veículos de passeio, apenas. 


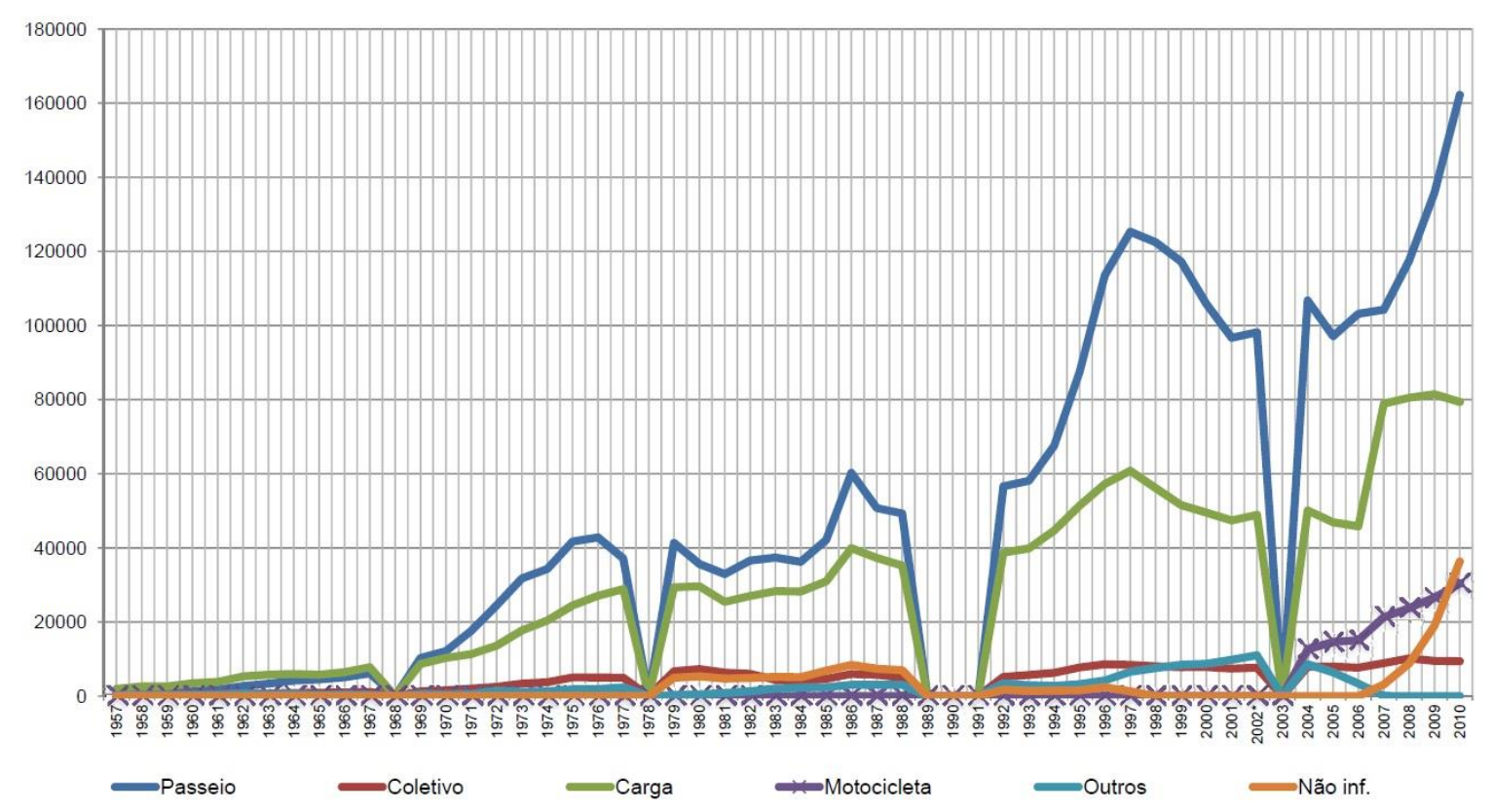

Figura 2 - Veículos acidentados nas rodovias federais segundo o tipo de veículo, de 1957 a 2010, Brasil. FONTE: Anuário estatístico das Rodovias Federais - Acidentes de Trânsito e Ações de Enfrentamento ao Crime, DNIT, 2010.

Segundo o DENATRAN ${ }^{50}$, a frota brasileira foi de 81.600 .729 veículos automotores em 2013. No mesmo ano foram registrados quase 2,5 milhões de caminhões, o equivalente a $3 \%$ da frota nacional. Porém, apesar desta baixa porcentagem na participação no número total de veículos, o transporte de cargas é responsável por $25 \%$ dos acidentes ocorridos nas rodovias ${ }^{51}$ e responde sozinho por $15 \%$ dos óbitos e $7 \%$ dos casos de invalidez permanente ${ }^{52}$.

Em 2006, a Secretaria de Estado dos Transportes de São Paulo ${ }^{53}$ estimou que o transporte rodoviário de cargas correspondia a $90 \%$ da demanda de transportes no país. O relatório executivo anual desenvolvido por esta instituição descreveu um percentual relativamente elevado de caminhões trafegando na malha rodoviária: um caminhão para cada 2,7 automóveis. 
O transporte rodoviário de cargas é realizado de diversas formas: empresas transportadoras; pessoas físicas que prestam serviço a terceiros com veículo próprio; pessoas físicas que utilizam veículo próprio no transporte rodoviário de forma complementar à sua atividade principal e empresas de carga própria ${ }^{54}$.

Para exercer a atividade econômica do transporte rodoviário de cargas é necessário que o motorista possua o Registro Nacional de Transportadores Rodoviários de Cargas (RNTRC). O transporte de cargas é caracterizado como aquele que é realizado em vias públicas, no território nacional, por conta de terceiros e mediante remuneração, exercido por pessoa física ou jurídica em regime de livre concorrência. O RNTRC contempla transportadores cadastrados em três categorias ${ }^{55}$ :

- Empresas de Transporte Rodoviário de Cargas;

- Cooperativas de Transporte Rodoviário de Cargas;

- Transportadores Autônomos de Cargas.

As diversas formas de vínculo empregatício podem apresentar particularidades em relação à organização do trabalho tais como metas, prazos, jornada de trabalho, pausas, entre outros aspectos.

Existem dois tipos de esquema de trabalho ${ }^{56}$ :

- horários irregulares: motoristas trabalham de acordo com a demanda;

- horários regulares: trabalhadores seguem uma escala predeterminada de horários de trabalho. 
Os horários irregulares de trabalho, incluindo o trabalho noturno, afetam a segurança dos motoristas de caminhão ao volante. Em 2003, um estudo demonstrou que o grupo de motoristas que trabalhavam em horários irregulares apresentaram mais episódios de sono em relação aos motoristas que trabalhavam em turnos fixos ${ }^{57}$. Os autores afirmaram que grande parte dos AT são decorrentes da sonolência excessiva, resultante de débitos de sono. Os mesmos autores ${ }^{58}$ também fizeram um estudo com 50 motoristas de caminhão e investigaram os hábitos alimentares e de sono dos profissionais que trabalham em horário irregular e em horário fixo-diurno. A pesquisa mostrou que os trabalhadores que atuam em horário irregular consumiam mais estimulantes do sistema nervoso $(83,3 \%)$ em relação aos motoristas que trabalhavam em horário fixo (6,3\%).

Outro estudo realizado com 400 motoristas de caminhão no interior de São Paulo, verificou que 59,5\% dos trabalhadores eram autônomos e 58,5\% faziam viagens curtas (no limite do estado); trabalhavam em média 12,7 horas diárias e dormiam de 5 a 8 horas por dia ${ }^{59}$. Os autores mostraram que 0 estresse emocional, a depressão, a angústia e a ansiedade estavam relacionados à privação de sono e cansaço decorrentes das longas jornadas de trabalho. Com o tempo de sono e descanso comprometidos, os efeitos negativos poderiam afetar a saúde física e mental dos motoristas e gerar prejuízos musculares e posturais, ocasionando sintomas como tensão, fadiga, câimbras e dores.

Em 2010, foi realizado um estudo ${ }^{60}$ semelhante com 513 motoristas de caminhão, que mostrou que a insegurança no trabalho é uma das maiores 
fontes de preocupação e estresse dos trabalhadores. Os autores descreveram que as constantes preocupações com segurança, acidentes e pressão das empresas para cumprimento dos prazos poderiam desencadear doenças ligadas ao estado emocional do motorista como estresse, nervosismo e irritabilidade. Os autores destacaram ainda que a baixa remuneração dos serviços fazia com que os profissionais trabalhassem num período de tempo cada vez maior, descuidando-se da manutenção do veículo e da velocidade permitida nas estradas. Desse modo, colocava em risco não somente sua integridade, como também a dos demais motoristas que cruzam as rodovias nacionais. Para cumprir os prazos de entrega estabelecidos pelas empresas, muitos motoristas permaneciam acordados por longas horas, o que terminava por influenciar seu desempenho ao volante, diminuindo a capacidade de reação e, consequentemente, aumentando o risco de AT.

Esse tipo de pressão também é relatado pelos trabalhadores autônomos, pois eles devem realizar o maior número de entregas possível em um menor tempo. No trabalho autônomo, a renda obtida depende, exclusivamente, da capacidade do trabalhador em realizar suas atividades, sugerindo que exista uma cobrança de trabalho sentida pelo próprio profissional em realizar o quanto antes seus afazeres. Essa pressão implica na velocidade de realização da tarefa, o que, por sua vez, está diretamente ligado a uma maior exposição ao risco deste trabalhador se acidentar ${ }^{61}$. 


\subsubsection{Aspectos laborais dos caminhoneiros e uso de drogas}

Apesar da dificuldade em determinar as causas que levam motoristas de caminhão a se acidentar, é possível observar fatores de risco: as falhas mecânicas do veículo; as condições precárias das rodovias; privação de sono; fadiga e uso abusivo de anfetaminas e cafeína como estratégias para se manterem acordados; a pressão para o cumprimento dos prazos e horários de trabalho impostos pelas empresas ${ }^{62}$.

Essa pressão pela necessidade de cumprir os prazos de entrega de cargas faz com que os motoristas de caminhão recorram ao uso de café, bebidas energéticas e "rebites" para evitar as necessárias paradas para 0 descanso e o sono durante o trabalho. Os motoristas dirigem sob a influência de derivados anfetamínicos, muitas vezes associados ao álcool e a outras drogas $^{63}$. Para reduzir o cansaço e o sono em viagens de longas distâncias, os trabalhadores frequentemente recorrem ao uso dessas substâncias ${ }^{39}$.

O uso de álcool e outras drogas é um dos principais contribuintes para a ocorrência de AT. Entre os veículos automotores, caminhões são o segundo mais prevalente em termos de total de acidentes e custos. Assim, o uso de álcool e outras drogas entre caminhoneiros é uma causa especial de preocupação. As substâncias são usadas de tal maneira que a atividade ocupacional torna-se perigosa, com potenciais consequências negativas para a saúde pública brasileira, judiciária e sistemas de segurança social, além da sociedade como um todo ${ }^{20}$.

Os motoristas ainda relatam o cansaço mental e físico como aspectos que contribuem para os AT. Em relação aos aspectos mentais, os motoristas 
revelam que o tempo longe de casa e da família, as preocupações relativas ao pagamento das parcelas do caminhão e a demora no carregamento e descarregamento das cargas são aspectos que causam o esgotamento mental e que se relacionam aos AT. Já quanto aos aspectos físicos, referem-se ao sono e ao cansaço decorrentes das longas jornadas de trabalho, que não apenas levam ao AT, como também conduzem os motoristas a utilizarem substâncias químicas para se manterem acordados durante sua atividade ${ }^{52}$.

\subsubsection{Prevalência do uso de drogas por caminhoneiros}

A urina é uma matriz biológica utilizada para se analisar o uso de drogas de abuso em estudos epidemiológicos. A utilização da urina justifica-se por ser uma matriz de fácil coleta, realizada de forma não-invasiva. A droga inalterada e/ou seus principais metabólitos são eliminados pela urina mesmo passados alguns dias após o consumo, por isso, essa matriz biológica reflete o uso recente da substância pesquisada 64 .

Na literatura científica, alguns estudos relacionam o uso de substâncias psicoativas com a direção do caminhão ou com a ocorrência de AT. Em 1993, nos Estados Unidos ${ }^{65}$, ao analisarem os motoristas profissionais vítimas de acidentes fatais, verificou-se que $13 \%$ deles tinham feito uso de bebidas alcoólicas e outros $28 \%$ haviam feito uso de drogas: cannabis (13\%), cocaína $(8 \%)$ e anfetamina $(7 \%)$.

Uma pesquisa em 2008, na França ${ }^{66}$, testou a urina de 1.000 caminhoneiros e os resultados indicaram que mais de $9 \%$ deles haviam feito uso de álcool e/ou outras drogas. Considerando o consumo pelos motoristas do 
grupo estudado, a cannabis (8,5\%) foi mais utilizada que o álcool (5\%). Também foram encontradas anfetamina $(0,3 \%)$ e cocaína $(0,1 \%)$.

Em pesquisa realizada em 2012, na Noruega ${ }^{67}$, pesquisadores afirmaram que o uso de substâncias psicoativas por motoristas de caminhão é menor que os números encontrados em outros países. Os resultados mostraram que álcool e outras drogas foram encontrados em 1,9\% das amostras coletadas de motoristas particulares e em 6,6\% dos motoristas de caminhão.

Já no Brasil não existem estudos sobre o uso de drogas por caminhoneiros e a sua associação com a ocorrência de AT. A maioria dos estudos existentes descreve a prevalência do uso de drogas, baseada em relatos dos motoristas ou mesmo por resultados de análises toxicológicas, porém não são diretamente relacionados com a ocorrência de AT. A diferença de metodologia entre os estudos existentes (coleta de informações e/ou análises entre diferentes amostras biológicas) tem limitado a comparação de resultados e a construção de um cenário mais fiel à realidade. A seguir, estão descritos alguns estudos brasileiros sobre o uso de drogas por caminhoneiros.

Zeferino $(2004)^{68}$, em estudo realizado em empresas de transporte em Santa Catarina, verificou que em $96 \%$ destas os motoristas já sofreram AT, resultando em morte ou lesão permanente. A autora afirma que este índice de acidentalidade pode ser influenciado pelo uso de drogas, pois $48 \%$ dos motoristas entrevistados responderam que fazem uso de drogas. Já no estudo de Silva-Junior et al. $(2009)^{69}, 35 \%$ dos caminhoneiros entrevistados relataram usar anfetaminas. 
Em 2002, Leyton et al. ${ }^{70}$ discorreram sobre o uso de anfetamínicos pelos motoristas de caminhão e os efeitos dessas substâncias na saúde. Dentre as diversas medicações utilizadas pelos motoristas de caminhão estavam o Dualid $^{\circledR}$ (cloridrato de anfepramona), Desobesi-M e o Lipomax (cloridrato de femproporex). Um fato preocupante é observar que no Brasil, o uso destes derivados anfetamínicos entre os motoristas de caminhão, entre eles o femproporex e a anfepramona (indicados para o controle de obesidade) é empregado para reduzir o sono, aumentar a jornada de trabalho, rendimento e produtividade. Os motoristas que recorrem às anfetaminas para se manterem acordados estão propensos a dormir ao volante quando o efeito estimulante da droga cessa e então podem provocar acidentes de trânsito nas estradas ${ }^{39}$.

Ainda em 2002, Villarinho et al. ${ }^{71}$ realizou uma pesquisa na cidade de Santos com 279 caminhoneiros e revelaram que, dentre as drogas utilizadas pelos trabalhadores, estavam o consumo de álcool (84\%), cannabis (33\%), rebite $(20 \%)$, cocaína $(12 \%)$, calmantes $(5 \%)$, cola $(4 \%)$, LSD $(3 \%)$ e crack $(1,5 \%)$.

Yonamine et al. ${ }^{72}$ realizou um estudo no estado de São Paulo, durante os anos de 2002 a 2008, utilizando fluido oral como amostra biológica. Foram coletadas 1.250 amostras de caminhoneiros e as análises toxicológicas indicaram que $3,1 \%(n=39)$ foram positivas para as seguintes drogas: $0,64 \%$ anfetaminas; $0,56 \%$ cocaína e $0,4 \%$ cannabis. Um caso foi positivo para cocaína e cannabis e o restante das amostras positivas (1,44\%) para álcool.

Em 2003, Silva et al. ${ }^{73}$ publicaram um estudo realizado com amostras de urina de motoristas profissionais, oriundos de três regiões do Brasil, coletadas 
entre os anos de 1996 a 2003. Das 728 amostras, 41 (5,63\%) apresentaram resultados positivos para as drogas pesquisadas: $4,8 \%$ anfetaminas; $0,27 \%$ cocaína; $0,27 \%$ cannabis e outros $0,27 \%$ apresentaram uso concomitante de duas drogas. As drogas pesquisadas foram escolhidas em particular porque exercem influência na habilidade da direção segura.

Um estudo realizado em Minas Gerais por Nascimento et al. ${ }^{39}$, em 2005, indicou que $27 \%$ dos motoristas profissionais que usavam anfetaminas já tinham se envolvido em AT na vida. Esse índice foi mais alto do que aquele relacionado com o uso de álcool (17\%). O estudo compilou relatos de 91 motoristas e mostrou que $91 \%$ ingeriam bebidas alcoólicas e $66 \%$ usavam anfetamina. $\mathrm{O}$ uso da droga associava-se à longa jornada de trabalho, que ocorria devido a fatores socioeconômicos como dívidas pessoais, crise no setor de transportes e exigências de entregas de cargas em curto prazo. Como a maioria dos entrevistados disse que prefere viajar à noite ou durante as madrugadas e relata dormir menos de 6 horas por dia, os autores concluíram que existe uma forte associação entre o período de trafegar e o uso de anfetaminas, sugerindo que o período noturno seja uma variável determinante para o uso dessa droga.

No ano seguinte, em 2006, outro estudo foi realizado por Knauth et al. ${ }^{74}$, no Rio Grande do Sul que objetivou analisar os fatores associados com o uso de estimulantes por caminhoneiros. Foi aplicado um questionário em 854 motoristas e 12,4\% afirmaram usar anfetaminas, consumindo-a isoladamente ou associada com café, pó de guaraná, bebidas energéticas e cocaína. Esse uso foi associado a motoristas jovens, com salários maiores, viagens longas e 
uso de álcool. Os ganhos mais elevados de alguns motoristas são resultado de uma carga de trabalho aumentada, o que pode resultar em estresse físico e emocional, com consequente uso de estimulantes como solução temporária.

Em 2009, em estudo realizado no Estado de São Paulo por Leyton et al. ${ }^{75}$, analisando amostras de urina de 452 motoristas foi apontado que 9,3\% deles apresentaram resultados positivos para uso de drogas. A substância com maior frequência de uso foi a anfetamina $(5,8 \%)$, seguida pela cocaína $(2,2 \%)$ e cannabis $(1,1 \%)$.

O problema se agrava quando se analisa o conhecimento dos usuários de anfetaminas sobre os riscos e consequências desse uso. Estudo de Moreira \& Gadani $^{76}$, em 2009, mostrou que dos $65 \%$ dos motoristas que relataram fazer o uso de "rebite", 43\% confessaram não ter conhecimento sobre suas consequências. Por outro lado, a maioria (57\%) respondeu que sabe sobre os efeitos e seus riscos, mas mesmo assim, pelo medo de perder o emprego, se arriscam e percorrem em média 2.200 quilômetros e vão de uma cidade a outra em 24 horas.

Em 2010, outro estudo realizado por Takitane et al. ${ }^{77}$ em rodovias do Estado de São Paulo através de análises toxicológicas em urinas de caminhoneiros ( $n=130$ ), mostrou que $10,8 \%$ dos motoristas haviam feito uso de anfetaminas.

Em 2011, Silva ${ }^{52}$ realizou um levantamento com caminhoneiros, baseado em relatos dos motoristas a respeito da relação entre o vínculo empregatício e a ocorrência de acidentes de trabalho. A autora descreveu que caminhoneiros de ambos os vínculos empregatícios afirmaram que, atualmente, mais que o 
rebite, está o consumo exacerbado da cocaína e do crack pela maioria dos motoristas de caminhão nas estradas. Os trabalhadores relataram que o uso dessas substâncias se dá pelos mesmos motivos do uso do rebite: ficar acordado para cumprir os prazos de entrega.

No ano de 2012 dois estudos foram realizados seguindo a mesma metodologia. O primeiro foi feito por Peixe et al. ${ }^{78}$, no Porto de Paranaguá, no Estado do Paraná, que analisou a urina de 62 caminhoneiros e obteve positividade em $8,1 \%$ dos casos: $4,8 \%$ para cocaína, 1,6\% para anfetaminas e $1,6 \%$ para ambas. Dentre os motoristas estudados, não foi constatado o consumo de cannabis. $\mathrm{O}$ trabalho também mostrou que o consumo de drogas foi mais prevalente entre os caminhoneiros que relataram sofrer AT no ano anterior. O segundo estudo foi realizado por Oliveira et al. ${ }^{79} \mathrm{em}$ estradas do Estado de São Paulo e objetivou identificar o uso de anfetaminas entre os caminhoneiros após a implementação da RDC № 52/201140. Foram coletadas urinas de 427 caminhoneiros e as análises toxicológicas demonstraram positividade em $7 \%$ dos casos, sendo $2,7 \%$ para anfetaminas, indicando que a despeito da proibição, o uso de anfetaminas continuava vigente.

O trabalho mais recente sobre o tema foi publicado em 2015 por Sinagawa et al..$^{80}$ e traz dados de análises toxicológicas em urina coletadas de motoristas $(n=993)$ entre os anos de 2008 a 2011. Os resultados mostraram positividade de $5,4 \%$ para anfetaminas, 2,6\% para cocaína e 1,0\% para cannabis. Já segundo os relatos dos motoristas, a porcentagem de uso das mesmas drogas seria de 5,7\% para anfetaminas, 0,7\% para cocaína e 0,3\% para cannabis, indicando que os entrevistados não relataram o uso de maneira 
confiável. O estudo também mostrou uma associação significativa entre o consumo de anfetaminas e a distância percorrida, quanto mais longa a viagem, maior o uso desta droga.

\subsection{Comandos de Saúde nas Rodovias}

Os "Comandos de Saúde nas Rodovias" (CSR) são campanhas educativas organizadas pelo Departamento de Polícia Rodoviária Federal (DPRF) em parceria com o Serviço Social do Transporte e Serviço Nacional de Aprendizagem no Transporte (SEST SENAT) que têm por finalidade reforçar, junto aos profissionais do transporte, a necessidade de manutenção da saúde. As campanhas têm sido voltadas aos trabalhadores de empresas de transporte rodoviário e transportadores autônomos.

Através dessa iniciativa, motoristas de caminhão têm sido abordados à beira da estrada e têm recebido, gratuitamente, avaliação de pressão arterial, frequência cardíaca, índice de massa corpórea, glicemia, acuidade visual, auditiva e força manual, assim como orientação sobre um estilo de vida saudável. As aferições ajudam a detectar possíveis fatores de risco à saúde como pressão alta, obesidade e sonolência excessiva diurna. Ao final dos exames, o motorista é encaminhado para uma consulta médica. Aqueles que apresentam algum problema são orientados a procurar atendimento médico especializado. Se a condição de saúde não permite que o motorista continue dirigindo (exemplo: glicemia elevada ou pressão demasiadamente alta), ele é atendido pela equipe médica do evento e então deve aguardar no local até estar apto para seguir viagem. 
O objetivo do evento é avaliar a saúde desses profissionais e orientá-los sobre a importância da realização de exames periódicos. A campanha visa promover a saúde do caminhoneiro, a fim de tentar evitar acidentes de trânsito e também obter indicadores estatísticos sobre o perfil de saúde destes motoristas.

Os CSR acontecem quatro vezes ao ano, concomitantemente em todos os estados brasileiros. Desde 2008, a equipe de pesquisadores do Laboratório de Toxicologia do Departamento de Medicina Legal, Ética Médica e Medicina Social e do Trabalho da FMUSP (LT-FMUSP), tem participado dos CSR coletando urina dos motoristas para estimar o uso de substâncias psicoativas (anfetaminas, cocaína e cannabis) pela categoria através da realização de análises toxicológicas.

\subsection{Justificativa}

Em suma, os itens descritos nesta introdução subsidiam os motivos para a realização do presente estudo. Há poucas pesquisas brasileiras sobre o uso indiscriminado de substâncias psicoativas por motoristas de caminhão e sobre a relação desse uso com outros fatores de risco que podem levar à ocorrência de acidentes de trânsito. Portanto, os resultados obtidos dessa pesquisa, além de servirem de base para publicações científicas, também permitirão às autoridades brasileiras responsáveis pela segurança no trânsito conhecer a frequência do uso de drogas por caminhoneiros para assim, propor medidas visando à redução de AT no país. 
Este trabalho busca fornecer dados que sirvam de parâmetro para: (a) reforçar ou reorientar esforços para medidas preventivas que possam ser aplicadas a esses trabalhadores, (b) para que medidas de fiscalização, monitoramento, controle e políticas públicas sejam reforçadas ou planejadas pelos órgãos competentes, e, finalmente (c) para aumentar a segurança no trânsito e assim minimizar os AT no Brasil, bem como o ônus a eles relacionados. 


\section{OBJETIVOS}

\subsection{Objetivo geral}

Estimar a prevalência de uso de substâncias psicoativas (anfetaminas, cocaína e cannabis) entre motoristas de caminhão que trafegam em rodovias do Estado de São Paulo através de análise toxicológica em urina, assim como levantar os dados sociodemográficos e ocupacionais destes profissionais para avaliar a associação com os resultados toxicológicos.

\subsection{Objetivos específicos}

- Aplicar um instrumento de pesquisa estruturado para levantar informações sociodemográficas e ocupacionais para traçar o perfil do motorista de caminhão;

- Realizar a análise toxicológica nas amostras de urina dos motoristas de caminhão, coletadas durante os CSR promovidos pelo DPRF no Estado de São Paulo, para determinação da presença de anfetaminas, benzoilecgonina (metabólito da cocaína) e THC-COOH (metabólito do THC, princípio ativo da cannabis);

- Buscar associações entre o consumo das drogas pesquisadas com as variáveis obtidas nos questionários aplicados nos motoristas. 


\section{MÉTODOS}

Este trabalho foi um estudo observacional do tipo transversal sobre o uso de drogas (anfetaminas, cocaína e cannabis) entre caminhoneiros que circularam nas rodovias do Estado de São Paulo.

O projeto original foi desenvolvido pela equipe de pesquisadores do LTFMUSP em parceria com o DPRF desde o ano de 2008.

Os locais e datas para a realização dos CSR foram determinados pelo DPRF ao início de cada ano.

\subsection{Amostragem}

\subsubsection{Casuística}

Foram abordados 1.368 caminhoneiros, dos quais $1.316 \quad(96,2 \%)$ aceitaram participar da pesquisa.

A coleta dos dados e de urina dos motoristas participantes foi realizada durante os CSR, em diferentes estradas que atravessam o Estado de São Paulo, durante os anos de 2008 a 2012.

A quantidade de amostras coletadas e o número de recusas em cada CSR estão distribuídos de acordo com a Tabela 1. 
Tabela 1 - Número de amostras coletadas e recusas de caminhoneiros segundo algumas características (município, rodovia e data), Estado de São Paulo, 2008 a 2012.

\begin{tabular}{|c|c|c|c|c|}
\hline Município & Rodovia & Data & Amostras & Recusas \\
\hline Itapecerica da Serra & $\begin{array}{l}\text { Regis Bittencourt } \\
\text { (km 296) }\end{array}$ & $14 / 11 / 08$ & 48 & 10 \\
\hline Roseira & $\begin{array}{l}\text { Presidente Dutra } \\
\qquad(\mathrm{km} \mathrm{78)}\end{array}$ & $18 / 03 / 09$ & 66 & 3 \\
\hline Atibaia & $\begin{array}{c}\text { Fernão Dias } \\
(\mathrm{km} \mathrm{45)}\end{array}$ & $30 / 06 / 09$ & 88 & 7 \\
\hline Guarulhos & $\begin{array}{l}\text { Presidente Dutra } \\
\quad(\mathrm{km} \mathrm{210)}\end{array}$ & $17 / 09 / 09$ & 82 & 5 \\
\hline Itapecerica da Serra & $\begin{array}{l}\text { Regis Bittencourt } \\
\text { (km 287) }\end{array}$ & 01/12/09 & 65 & 5 \\
\hline Itapecerica da Serra & $\begin{array}{l}\text { Regis Bittencourt } \\
\quad(\mathrm{km} \mathrm{299})\end{array}$ & $14 / 04 / 10$ & 72 & 2 \\
\hline Marília & $\begin{array}{c}\text { Transbrasiliana } \\
\text { (km 259) }\end{array}$ & $30 / 06 / 10$ & 58 & 2 \\
\hline Cachoeira Paulista & $\begin{array}{l}\text { Presidente Dutra } \\
\text { (km 58) }\end{array}$ & $24 / 11 / 10$ & 83 & 4 \\
\hline Atibaia & $\begin{array}{c}\text { Fernão Dias } \\
(\mathrm{km} \mathrm{47)}\end{array}$ & $11 / 05 / 11$ & 143 & 3 \\
\hline Itapecerica da Serra & $\begin{array}{l}\text { Regis Bittencourt } \\
\quad(\mathrm{km} \mathrm{297)}\end{array}$ & $17 / 08 / 11$ & 91 & 4 \\
\hline S. José dos Campos & $\begin{array}{l}\text { Presidente Dutra } \\
\text { (km 156) }\end{array}$ & $01 / 12 / 11$ & 110 & 3 \\
\hline Atibaia & $\begin{array}{c}\text { Fernão Dias } \\
(\mathrm{km} \mathrm{48)}\end{array}$ & $18 / 04 / 12$ & 129 & 2 \\
\hline Marília & $\begin{array}{c}\text { Transbrasiliana } \\
\text { (km 259) }\end{array}$ & $15 / 08 / 12$ & 152 & 1 \\
\hline Itapecerica da Serra & $\begin{array}{l}\text { Regis Bittencourt } \\
\quad(\mathrm{km} \mathrm{297)}\end{array}$ & $28 / 11 / 12$ & 129 & 1 \\
\hline TOTAL & & & 1.316 & 52 \\
\hline
\end{tabular}

No item resultados, será descrita a prevalência do uso de drogas ao longo destes cinco anos $(n=1.316)$ para apresentar a análise histórica do padrão de consumo de drogas pelos caminhoneiros. Porém, para as demais análises estatísticas, foram consideradas somente as coletas realizadas no ano de 2012 
( $\mathrm{n}=410)$. Essa restrição nas análises estatísticas somente para o ano de 2012 foi realizada porque os resultados deste ano específico refletem os mesmos achados do número total (2008 a 2012). Não foi um ano atípico, considerando os achados toxicológicos e o perfil do motorista é o mesmo encontrado ao longo dos anos; além disso, os dados a serem expostos são mais recentes. Esse corte foi realizado para ajustar as análises e a amostra de 400 caminhoneiros foi obtida baseada em uma proporção de uso de drogas estimada em $10 \%$, com precisão relativa especificada de $30 \%$ (Alfa $=0,05)$.

O ano de 2012 foi escolhido como linha de base para o corte nas análises para, posteriormente, em estudos futuros, permitir fazer um comparativo entre os anos anteriores e posteriores.

\subsection{Logística da coleta}

\subsubsection{Abordagem dos motoristas}

Inicialmente, os motoristas de caminhão foram abordados nas rodovias pelos policiais rodoviários federais e foram convidados a participar dos CSR. Os motoristas parados não eram suspeitos de estarem dirigindo sob o efeito de álcool ou drogas. Esse recrutamento foi realizado no período da manhã e início da tarde (das $9 \mathrm{~h}$ às $13 \mathrm{~h}$ ) em dias de semana. Alguns motoristas eram parados e os próximos eram sendo escolhidos à medida que havia espaço para estacionamento dos veículos no pátio do evento ou no acostamento da rodovia, dependendo da localidade, constituindo dessa forma uma amostra de conveniência não probabilística. 
Após participarem das atividades de saúde propostas pelo CSR, os motoristas foram convidados a participar da pesquisa sobre o "Uso de drogas psicoativas por motoristas profissionais no Estado de São Paulo". Eles foram informados pela equipe de coleta sobre o objetivo da pesquisa e sobre a necessidade do fornecimento de amostra de urina e resposta ao questionário, esclarecendo-se o caráter voluntário, o sigilo das informações e a não identificação dos mesmos.

\subsubsection{Coleta das informações}

Após a aceitação de participação pelo motorista, os pesquisadores fizeram a leitura do Termo de Consentimento Livre e Esclarecido (TCLE) (Anexo 1) e mediante a concordância de participar na pesquisa, o termo foi assinado.

Em seguida, os pesquisadores realizaram a entrevista, utilizando um instrumento de pesquisa (Anexo 2) para a coleta de dados, que abrange informações sociodemográficas e ocupacionais. Esse instrumento foi preenchido exclusivamente pelos pesquisadores e foi aplicado conforme a técnica "face-to-face" em local reservado ${ }^{81}$, longe da presença dos policiais. Esse distanciamento evitou que os motoristas se sentissem coagidos ao responderem questões sobre o uso de drogas, por exemplo.

As questões sociodemográficas objetivaram traçar o perfil destes motoristas e abrangiam dados como sexo, idade, estado civil, etnia observada e nível de escolaridade. O inquérito ocupacional investigou sobre o vínculo empregatício, tempo de profissão e duração da jornada de trabalho. Dados 
sobre a viagem como local de partida e destino, tipos de carga, número de horas já viajadas e tempo de descanso também foram coletados. Com relação aos aspectos de saúde, os dados coletados referiam-se à ausência/presença de hipertensão arterial, diabetes mellitus e estresse e também à prática de atividade física. Por fim, as questões que envolviam uso de álcool investigavam sobre a frequência deste uso e o relato de última vez de consumo.

\subsubsection{Coleta das amostras biológicas}

Após a entrevista, o motorista era encaminhado a um local reservado para realizar a coleta de urina. Foram coletados aproximadamente $50 \mathrm{~mL}$ de urina por micção espontânea em frascos de polietileno. Os mesmos foram identificados somente com um número (controle laboratorial interno), que era registrado também no questionário, fato necessário para a confrontação dos dados de resultado toxicológico e relatos sobre uso de drogas. É importante ressaltar que nem os instrumentos de pesquisa, tampouco as amostras de urina, foram identificadas com o nome do participante.

Após a coleta, as amostras de urina foram mantidas sob refrigeração em geladeiras térmicas e encaminhadas ao LT-FMUSP em um período máximo de 4 horas. A realização da primeira etapa das análises toxicológicas foi feita em no máximo 2 dias após a coleta, período no qual as amostras ficaram armazenadas em freezer a $-20^{\circ} \mathrm{C}$. 


\subsubsection{Critérios de inclusão e exclusão}

Foram incluídos no estudo os motoristas que concordaram em responder o instrumento de pesquisa e fornecer a amostra de urina. Aqueles que se negaram a contribuir com uma dessas condições foram desconsiderados da amostragem.

As recusas de participação foram todas registradas. No total de todos os anos, houve 52 motoristas que se recusaram a participar do estudo, representando $3,8 \%$ do total de motoristas abordados ( $n=1.368)$. O número de recusas está distribuído ao longo dos anos de acordo com a tabela 1. Dentre os motivos de recusa, o principal e mais alegado foi a falta de tempo devido à urgência na entrega da carga.

\subsection{Análise toxicológica}

A verificação do uso recente de anfetaminas, cocaína e cannabis foi realizada através da análise toxicológica das amostras de urina. A determinação da presença das substâncias inalteradas e/ou biotransformadas (pesquisa de seus metabólitos) deu-se através de dois procedimentos analíticos: triagem e confirmação do resultado.

\subsubsection{Triagem}

Esta primeira etapa foi realizada no LT-FMUSP através de testes de imunoensaio para as drogas pesquisadas. Foi utilizado o teste rápido para detecção de drogas "Multi-Drug One Step Test" (Inlab, São Paulo) conforme 
ilustrado pela Figura 3. A ausência do traço colorido na linha T (teste) indica resultados positivos.

O teste apresenta os seguintes valores de cutoff: anfetamina/ metanfetamina - $1000 \mathrm{ng} / \mathrm{mL}$, benzoilecgonina (metabólito da cocaína) - 300 ng/mL, COOH-THC (metabólito do THC, princípio ativo da cannabis) - 50 $\mathrm{ng} / \mathrm{mL}$.

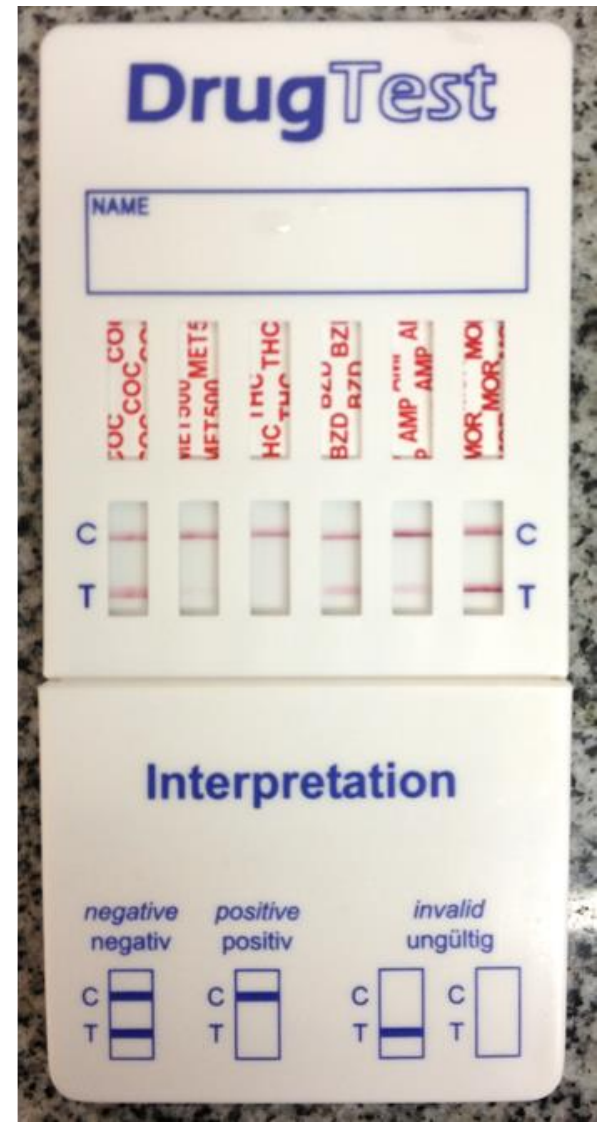

Figura 3 - Teste de imunoensaio utilizado na etapa de triagem. A amostra da foto apresentou resultado positivo para cannabis (coluna THC). 


\subsubsection{Confirmação}

As amostras que apresentaram resultado positivo na etapa de triagem foram enviadas ao Laboratório de Análises Toxicológicas da Faculdade de Ciências Farmacêuticas da Universidade de São Paulo (LAT-FCF-USP) para confirmação.

As amostras foram então submetidas a processos de extração líquidolíquido e extração em fase sólida e análise por cromatografia em fase gasosa acoplada à espectrometria de massas (CG/EM), com equipamento da marca Shimadzu ${ }^{\circledR}$, modelo QP 2010, utilizando método previamente publicado ${ }^{82,83}$.

Os seguintes valores de cutoff foram utilizados: anfetamina/ metanfetamina - $500 \mathrm{ng} / \mathrm{mL}$, benzoilecgonina - $150 \mathrm{ng} / \mathrm{mL}$ e 11-nortetraidrocanabinol carboxílico - $15 \mathrm{ng} / \mathrm{mL}^{84}$.

\subsection{Análise estatística}

Os dados obtidos foram armazenados em banco de dados ao longo do período de coleta e então testes estatísticos apropriados foram aplicados para o cálculo dos resultados.

As diferenças de proporções e medianas foram calculadas usando o teste do chi-quadrado e o teste Kruskal-Wallis, respectivamente (Alfa=0,05).

\subsection{Considerações éticas}

O presente estudo obedeceu a todas as disposições descritas na Resolução 196/96 (versão 2012) ${ }^{85}$ do Conselho Nacional de Saúde (CNS), 
sobre diretrizes e normas de pesquisa envolvendo seres humanos. O projeto foi aprovado pela Comissão de Ética para Análise de Projetos de Pesquisa (CAPPesq) da Diretoria Clínica do Hospital das Clínicas e da Faculdade de Medicina da Universidade de São Paulo, sob Protocolo de Pesquisa 0093/09 (Anexo 3).

O TCLE assinado pelo participante, que implica na sua inclusão no estudo, ressalta a não identificação de cada indivíduo quanto aos resultados das dosagens laboratoriais em questão.

Os resultados das determinações de drogas na urina foram mantidos sob sigilo quanto à identificação dos motoristas, não sendo utilizados, em qualquer momento, como possível instrumento legal a favor ou contra o participante do estudo. 


\section{RESULTADOS}

\subsection{Resultado da análise toxicológica}

Entre os anos de 2008 a 2012, foram coletadas no total 1.316 amostras, das quais $7,8 \%(n=103)$ apresentaram resultado positivo para uma ou mais das drogas pesquisadas: $3,4 \%$ foram positivas para anfetaminas, $2,5 \%$ para benzoilecgonina (metabólito da cocaína), 1,1\% para THC-COOH (metabólito do THC, princípio ativo da cannabis) e 0,5\% para duas drogas.

As amostras estão distribuídas de acordo com o ano de coleta segundo a Tabela 2.

Tabela 2 - Amostras de urina de caminhoneiros ( $\mathrm{N}$ e \%) segundo resultado toxicológico, Estado de São Paulo, 2008 a 2012.

\begin{tabular}{c|c||cc}
\hline \multirow{2}{*}{ Ano } & \multirow{2}{*}{ Amostras } & \multicolumn{2}{|c}{ Positivos } \\
\cline { 3 - 4 } & & $\mathbf{n}$ & $\%$ \\
\hline \hline 2008 & 48 & 7 & 14,6 \\
\hline 2009 & 301 & 24 & 8,0 \\
\hline 2010 & 213 & 24 & 11,3 \\
\hline 2011 & 344 & 19 & 5,5 \\
\hline 2012 & 410 & 29 & 7,1 \\
\hline \hline TOTAL & 1316 & 103 & 7,8 \\
\hline \hline
\end{tabular}


As anfetaminas foram as drogas mais identificadas nas amostras, representando $3,4 \%$ do total. Considerando somente os casos positivos, a anfetamina foi detectada em $43,7 \%$ das amostras. A segunda droga mais identificada foi a cocaína, representando $35,9 \%$ do total de amostras positivas, seguida pela cannabis com $13,6 \%$. O restante dos casos positivos $(6,8 \%)$ foi de amostras de motoristas que fizeram uso múltiplo de drogas, que apresentaram combinação de: (a) anfetamina + cocaína; (b) anfetamina + cannabis ou (c) cocaína + cannabis.

A distribuição de amostras negativas $(n=1.213)$ e positivas $(n=103)$ pode ser vista na Figura 4. Ao lado, observa-se a porcentagem de positividade de cada droga dentre o total de amostras analisadas $(\mathrm{n}=1.316)$.

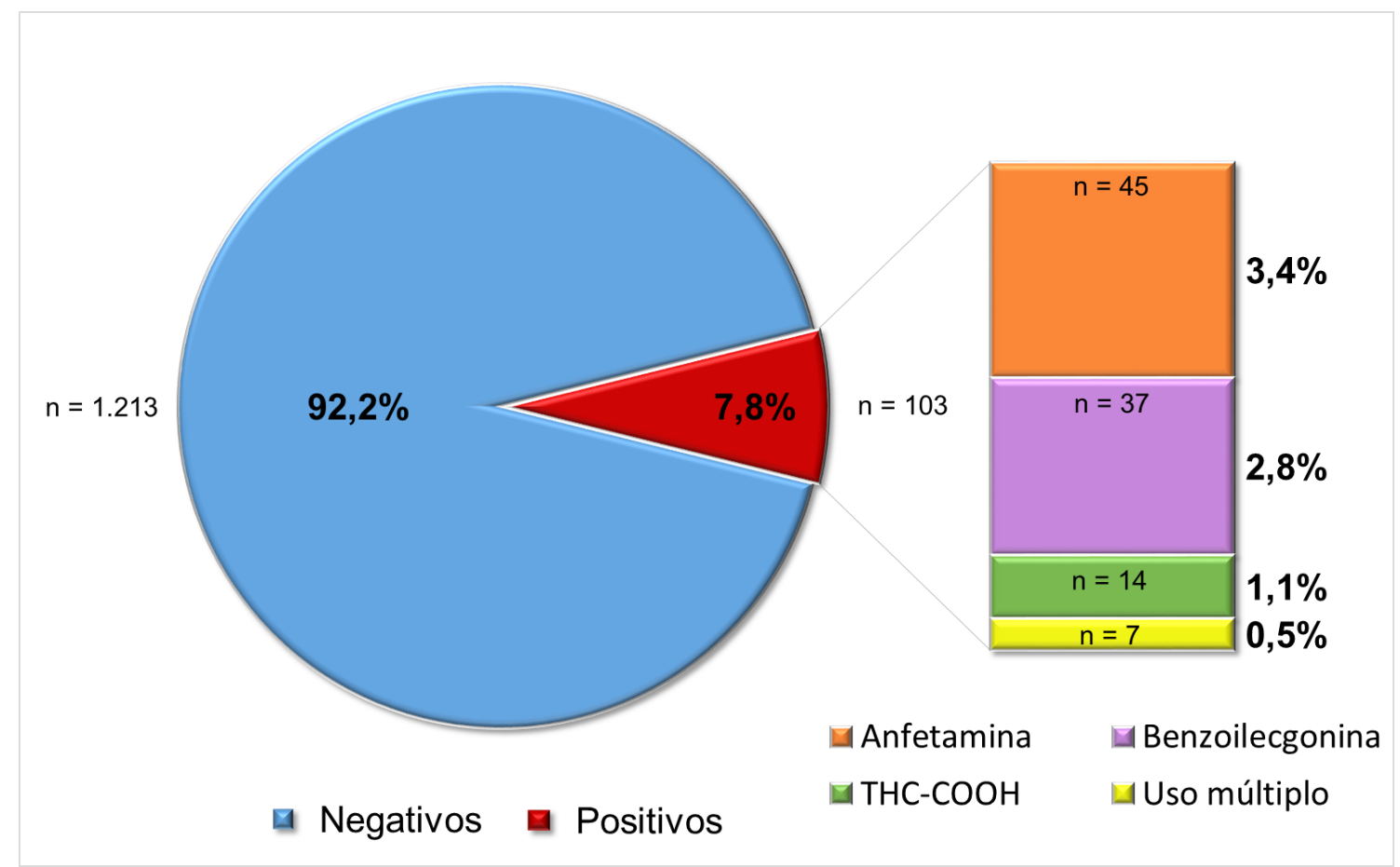

Figura 4 - Amostras de urina de caminhoneiros com resultados toxicológicos negativos $(n=1.213)$ e positivos $(n=103)$ de acordo com a droga, dentre o total de amostras coletadas $(n=1.316)$, Estado de São Paulo, 2008 a 2012. 
Com relação ao tipo de droga pesquisada no exame toxicológico, verificou-se o disposto na Tabela 3. Dentre os 103 casos positivos $(7,8 \%)$, ocorreram $96(93,2 \%)$ em que apenas uma droga foi detectada e 7 casos que apresentaram detecção de duas drogas, o que levou à constatação de 110 vezes em que o uso de drogas foi detectado, assim sendo: positividade para anfetamina: 50 (45,47\%); positividade para cocaína: 42 (38,2\%); positividade para cannabis: $18(16,47 \%)$.

Tabela 3 - Amostras de urina de caminhoneiros ( $\mathrm{N}$ e \%) segundo resultado toxicológico de acordo com o tipo de droga, Estado de São Paulo, 2008 a 2012.

\begin{tabular}{|c|c|c|c|c|c|c|c|c|c|c|c|c|}
\hline & \multicolumn{2}{|c|}{2008} & \multicolumn{2}{|c|}{2009} & \multicolumn{2}{|c|}{2010} & \multicolumn{2}{|c|}{2011} & \multicolumn{2}{|c|}{2012} & \multicolumn{2}{|c|}{ TOTAL } \\
\hline & $\mathbf{n}$ & $\%$ & $\mathbf{n}$ & $\%$ & $\mathbf{n}$ & $\%$ & $\mathbf{n}$ & $\%$ & $\mathbf{n}$ & $\%$ & $\mathbf{n}$ & $\%$ \\
\hline ANF & 6 & 12,5 & 10 & 3,3 & 17 & 8,0 & 6 & 1,7 & 6 & 1,5 & 45 & 3,4 \\
\hline $\mathrm{COC}$ & 1 & 2,1 & 9 & 3,0 & 5 & 2,4 & 9 & 2,6 & 13 & 3,2 & 37 & 2,8 \\
\hline MAC & - & - & 4 & 1,3 & - & - & 3 & 0,9 & 7 & 1,7 & 14 & 1,0 \\
\hline ANF/COC & - & - & 1 & 0,3 & 1 & 0,5 & - & - & 1 & 0,2 & 3 & 0,2 \\
\hline ANF/MAC & - & - & - & - & 1 & 0,5 & 1 & 0,3 & - & - & 2 & 0,1 \\
\hline $\mathrm{COC} / \mathrm{MAC}$ & - & - & - & - & - & - & - & - & 2 & 0,5 & 2 & 0,1 \\
\hline Total $(+)$ & 7 & 14,6 & 24 & 8,0 & 24 & 11,3 & 19 & 5,5 & 29 & 7,1 & 103 & 7,8 \\
\hline TOTAL & 48 & 100 & 301 & 100 & 213 & 100 & 344 & 100 & 410 & 100 & 1316 & 100 \\
\hline
\end{tabular}


Com exceção do ano de 2008, as três drogas pesquisadas foram encontradas em todos os anos da pesquisa, assim como o uso múltiplo de drogas. A combinação de anfetamina com cocaína representou $3 \%$ das amostras positivas.

Apesar de a anfetamina ter sido a droga mais utilizada dentre o número total de amostras, o padrão de consumo das drogas ao longo dos anos não foi uniforme. Nos primeiros três anos (2008-2010), a anfetamina foi a substância mais utilizada pelos motoristas, porém, nos dois anos seguintes, a cocaína passou a ser a droga mais consumida. A cannabis esteve presente em todos os anos do estudo, com exceção do ano de 2008.

A Figura 5 traz os mesmos resultados da Tabela 3, porém ilustrando a participação de cada droga, dentre o total de amostras positivas. As porcentagens são relativas ao total de amostras de cada ano.

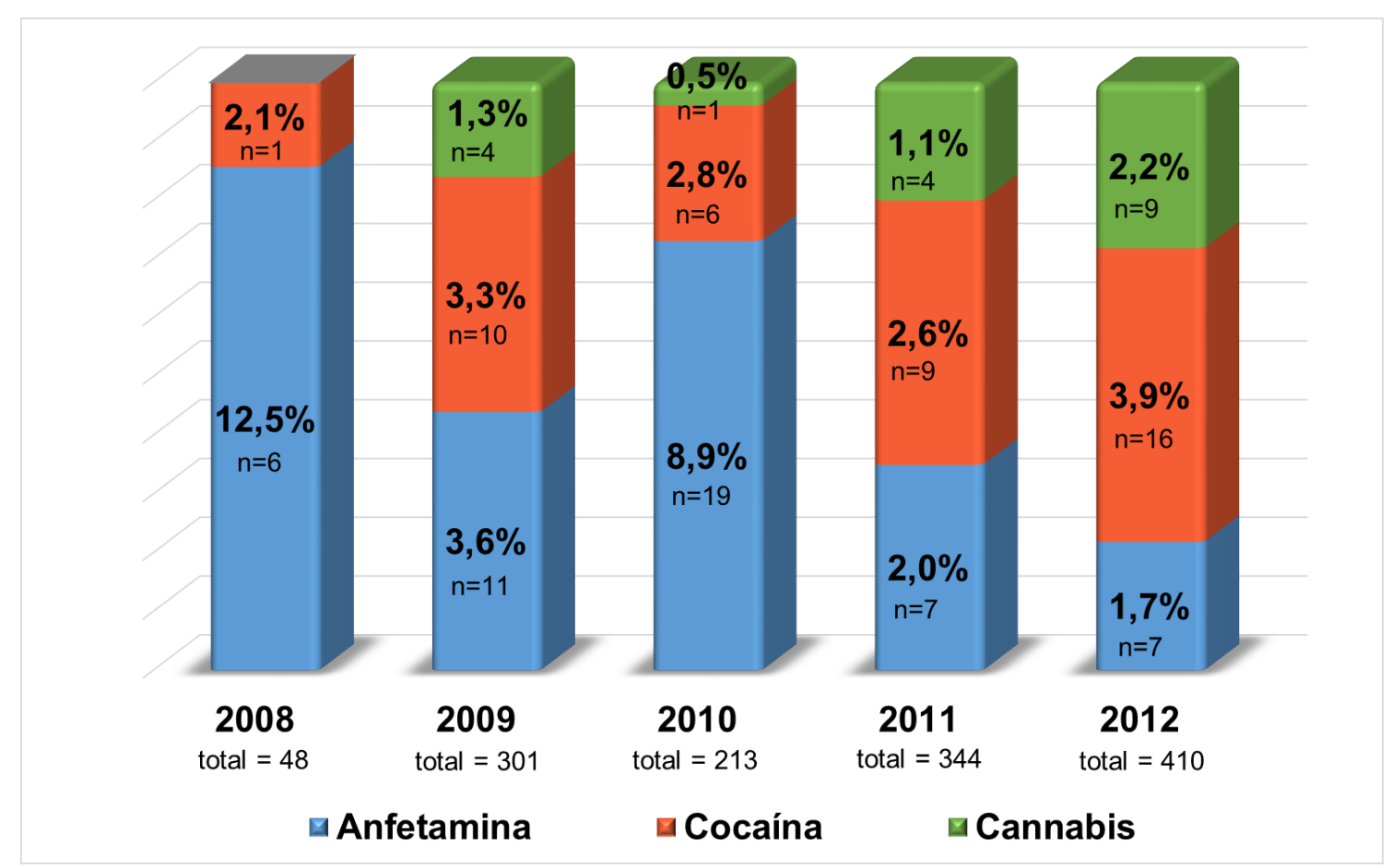

Figura 5 - Amostras de urina positivas de caminhoneiros distribuídas conforme 0 ano, segundo o tipo de droga e percentuais relativos ao total de amostras coletadas em cada ano, Estado de São Paulo, 2008 a 2012. 


\subsection{Perfil sociodemográfico dos motoristas}

O perfil do motorista apresentou uniformidade ao longo dos anos. A média de idade foi de $41 \pm 11$ anos (com mediana de 40 anos) e todos eram do sexo masculino. Os motoristas, em sua maioria, eram brancos $(93,5 \%)$ e casados (74,5\%). Quanto à escolaridade, $60 \%$ deles possuíam apenas o $1 \stackrel{\text { o grau }}{ }$ completo. A maioria (77\%) tinha mais de 5 anos de experiência e era contratada por empresas (62\%), segundo mostra a Tabela 4.

Tabela 4 - Perfil sociodemográfico dos caminhoneiros entrevistados ( $\mathrm{N}$ e \%), Estado de São Paulo, 2008 a 2012.

\begin{tabular}{|c|c|c|c|}
\hline \multicolumn{4}{|c|}{ Perfil geral dos motoristas } \\
\hline & $n^{*}$ & $\%$ & \\
\hline \multirow{2}{*}{$\begin{array}{l}\text { Estado civil } \\
\qquad(\mathrm{n}=1.311)\end{array}$} & 977 & 74,5 & Casado/amasiado \\
\hline & 334 & 25,5 & Solteiro \\
\hline \multirow{3}{*}{$\underset{(n=1.163)}{\text { Etnia }}$} & 1.087 & 93,5 & Branco \\
\hline & 65 & 5,5 & Negro \\
\hline & 11 & 1,0 & Amarelo \\
\hline \multirow{3}{*}{$\begin{array}{l}\text { Escolaridade } \\
\quad(n=1.315)\end{array}$} & 799 & 60,7 & 10 Grau \\
\hline & 473 & 36,0 & 2o Grau \\
\hline & 43 & 3,3 & Superior \\
\hline \multirow{2}{*}{$\begin{array}{c}\text { Tempo de profissão } \\
(\mathrm{n}=1.311)\end{array}$} & 1.013 & 77,3 & Mais que 5 anos \\
\hline & 298 & 22,7 & 5 anos ou menos \\
\hline \multirow{2}{*}{$\begin{array}{l}\text { Tipo de serviço } \\
(\mathrm{n}=1.304)\end{array}$} & 818 & 62,7 & Previdenciário \\
\hline & 486 & 37,3 & Autônomo \\
\hline
\end{tabular}

$\left(^{*}\right)$ as divergências quanto ao $\mathrm{N}$ obtido em cada uma das variáveis deve-se à ausência de preenchimento dos dados no questionário. 


\subsection{Análises com corte no ano de 2012}

Como descrito no item Métodos deste trabalho, foi realizado um corte no ano de 2012 ( $n=410)$ e a análise estatística dos resultados foi restringida a este ano, pois seus resultados (toxicológico e perfil dos motoristas) refletem os mesmos achados do número total (2008-2012).

A positividade no ano de 2012 foi de $7,1 \%(n=29)$ para todas as drogas pesquisadas. Porém, para o cálculo do intervalo de confiança de cada droga, considerou-se todas as vezes que o resultado foi positivo para alguma droga pesquisada.

Por esse motivo, os números da Tabela 5 não refletem o mesmo $\mathrm{N}$ e a mesma porcentagem descrita acima, pois incluem os casos de uso múltiplo de drogas.

Tabela 5 - Amostras de urina positivas de caminhoneiros ( $\mathrm{N}$ e \%) distribuídas de acordo com a droga e valores do intervalo de confiança, Estado de São Paulo, 2012.

\begin{tabular}{c||c|c|c}
\hline \hline Droga & $\mathbf{n}$ & $\%$ & Intervalo de confiança (95\%) \\
\hline Anfetamina & 7 & 1,7 & $0,4-2,9 \%$ \\
Cocaína & 16 & 3,9 & $2,0-5,7 \%$ \\
Cannabis & 9 & 2,1 & $0,7-3,6 \%$ \\
\hline \hline TOTAL & 32 & 7,7 & $4,5-9,5 \%$ \\
\hline \hline
\end{tabular}


O resultado da análise estatística se distribuiu de forma distinta de acordo com algumas variáveis sociodemográficas e com algumas características da viagem. As associações entre essas variáveis e o uso de drogas por caminhoneiros foram pesquisadas considerando-se apenas o consumo das drogas psicoativas estimulantes - a anfetamina e a cocaína - por serem usadas por motivos laborais segundo relatos dos próprios motoristas de caminhão. A cannabis sempre foi relatada por ser utilizada como uso recreativo, fora do turno de trabalho.

\subsubsection{Associação do resultado da análise toxicológica com as} variáveis relacionadas ao motorista

\section{Idade}

O uso de drogas estimulantes esteve associado à idade $(p=0,0047$; $\left.x^{2}=7,986\right)$ : observou-se que quanto maior era a idade do caminhoneiro, menor era a frequência do uso de drogas.

\section{Vínculo empregatício}

O consumo de drogas estimulantes apresentou-se de maneira distinta dependendo do vínculo empregatício dos caminhoneiros (Tabela 6), porém sem constatação de diferença estatisticamente significante $(p=0,374$; $\left.x^{2}=0,7917\right)$. Dentre os autônomos e contratados a positividade foi de $3,9 \%$ e $6,1 \%$ respectivamente. 
Tabela 6 - Amostras de urina de caminhoneiros ( $\mathrm{N}$ e \%) segundo resultado toxicológico (negativo ou positivo para anfetamina e cocaína) distribuídas de acordo com o vínculo empregatício referido, Estado de São Paulo, 2012.

\begin{tabular}{c|c|c|c}
\hline Vínculo empregatício & Positivos & Negativos & Total \\
\hline \hline \multirow{2}{*}{ Autônomos } & 5 & 122 & \multirow{2}{*}{127} \\
\cline { 2 - 4 } Contratados & $3,9 \%$ & $96,1 \%$ & \\
\hline TOTAL & 17 & 262 & \multirow{2}{*}{279} \\
\hline \hline
\end{tabular}

(*) em quatro casos, o vínculo empregatício foi ignorado.

\section{Tempo de profissão}

O tempo de profissão do caminhoneiro não esteve associado ao uso de drogas estimulantes $\left(p=0,052 ; x^{2}=5,9154\right)$, como mostra a tabela 7. A associação não foi estatisticamente significante, mas o valor de $p$ se mostrou bem próximo ao limite de significância estabelecida.

A positividade para as drogas estimulantes pesquisadas dentre os motoristas com menos de 5 anos de experiência profissional e dentre os que tinham de 5 a 10 anos foi de, respectivamente, 5,9\% e 10,7\%. Já para os motoristas mais experientes, com mais de 10 anos de tempo de serviço, a positividade foi de $3,4 \%$.

Tabela 7 - Amostras de urina de caminhoneiros ( $\mathrm{N}$ e \%) segundo resultado toxicológico (negativo ou positivo para anfetamina e cocaína) distribuídas de acordo com o tempo de serviço referido, Estado de São Paulo, 2012.

\begin{tabular}{c|cc|c}
\hline \hline Tempo de profissão & Positivos & Negativos & Total \\
\hline \multirow{2}{*}{ Menos que 5 anos } & 6 & 95 & \multirow{2}{*}{101} \\
\cline { 2 - 4 } 5 a 10 anos & $5,9 \%$ & $94,1 \%$ & \\
\cline { 2 - 4 } Mais que 10 anos & 8 & 67 & 75 \\
\cline { 2 - 4 } & $10,7 \%$ & $89,3 \%$ & 235 \\
\hline \hline
\end{tabular}

(*) em um caso, o tempo de serviço foi ignorado. 


\section{Estado civil}

O padrão de consumo das drogas estimulantes também apresentou diferença estatisticamente significante dependendo do estado civil do motorista $\left(p=0,006 ; x^{2}=7,5509\right)$.

Dentre os motoristas que declararam viver sozinhos (solteiros ou viúvos), $10,7 \%$ tiveram resultados positivos para drogas estimulantes nas análises toxicológicas.

Já dentre os que declararam ter uma parceira (casados ou amasiados), a positividade foi de $3,6 \%$.

\section{Escolaridade}

O consumo de drogas estimulantes apresentou-se de maneira distinta dependendo da escolaridade dos caminhoneiros, porém sem constatação de diferença estatisticamente significante $\left(p=0,206 ; x^{2}=3,1608\right)$.

Dentre os motoristas que tinham apenas o ensino fundamental completo, $7 \%(n=16)$ tiveram resultados positivos enquanto entre os motoristas com ensino médio completo, a positividade foi de $3,6 \%(n=6)$.

Todos os motoristas que possuíam ensino superior $(n=17)$ tiveram resultados negativos para as drogas estimulantes pesquisadas.

\section{Etnia}

A etnia não esteve associada ao uso de drogas estimulantes $(p=0,875$; $\left.x^{2}=0,2679\right)$. A distribuição dos casos positivos foi semelhante entre os brancos, pardos e negros, porém ausente nos caminhoneiros de etnia amarela. 


\section{Número de ocupantes}

Aos motoristas era perguntado se viajavam sozinhos ou tinham algum acompanhante no caminhão.

Apesar dos casos positivos e negativos terem se distribuído de forma aparentemente distinta entre os motoristas que viajavam sozinhos ou acompanhados (Tabela 8), esta variável não esteve associada ao consumo de drogas estimulantes $(p=0,7900)$.

Tabela 8 - Amostras de urina de caminhoneiros ( $\mathrm{N}$ e \%) segundo resultado toxicológico (negativo ou positivo para anfetamina e cocaína) distribuídas de acordo com o número de ocupantes referido, Estado de São Paulo, 2012.

\begin{tabular}{c|cc|c}
\hline \hline Número de ocupantes & Positivos & Negativos & Total \\
\hline \hline Sozinho & 16 & 291 & \multirow{2}{*}{307} \\
\cline { 2 - 4 } & $5,2 \%$ & $94,8 \%$ & \\
Acompanhados & 6 & 93 & 99 \\
\cline { 2 - 3 } & $6,1 \%$ & $93,9 \%$ & \multirow{4}{*}{$\mathbf{4 0 6}^{\star}$} \\
\hline \hline TOTAL & $\mathbf{2 2}$ & $\mathbf{3 8 4}$ & \multicolumn{2}{|c}{} \\
\hline \hline
\end{tabular}

$\left(^{\star}\right)$ em quatro casos, o número de ocupantes foi ignorado. 


\section{Tipo de carga}

O conteúdo da carga transportada pelos caminhoneiros não esteve associado ao consumo de substâncias estimulantes $(p=0,182)$. Os diferentes tipos de carga foram distribuídos em quatro categorias principais: alimento perecível, carga viva, alimento não perecível e outros tipos de carga (diversos) conforme mostra a Tabela 9. Alguns caminhões estavam vazios ou os motoristas não quiseram identificar a carga.

Tabela 9 - Amostras de urina de caminhoneiros ( $\mathrm{N}$ e \%) segundo resultado toxicológico (negativo ou positivo para anfetamina e cocaína) distribuídas de acordo com o tipo de carga referido, Estado de São Paulo, 2012.

\begin{tabular}{|c|c|c|c|}
\hline Tipo de carga & Positivos & Negativos & Total \\
\hline \multirow{2}{*}{ Alimento perecível } & 6 & 40 & \multirow{2}{*}{46} \\
\hline & $13 \%$ & $87 \%$ & \\
\hline \multirow{2}{*}{ Carga viva } & 0 & 7 & \multirow{2}{*}{7} \\
\hline & $0 \%$ & $100 \%$ & \\
\hline \multirow{2}{*}{ Alimento não perecível } & 2 & 46 & \multirow{2}{*}{48} \\
\hline & $4,2 \%$ & $95,8 \%$ & \\
\hline \multirow{2}{*}{ Vazio/Não identificado } & 2 & 42 & \multirow{2}{*}{44} \\
\hline & $4,5 \%$ & $95,5 \%$ & \\
\hline \multirow{2}{*}{ Diversos } & 12 & 251 & \multirow{2}{*}{263} \\
\hline & $4,6 \%$ & $95,4 \%$ & \\
\hline TOTAL & 22 & 386 & $408^{*}$ \\
\hline
\end{tabular}

$\left({ }^{\star}\right)$ em dois casos, o tipo de carga foi ignorado. 
A tabela 10 mostra as variáveis descritas até o momento, trazendo o resumo de associação, com os valores de $p$ e do chi-quadrado $\left(x^{2}\right)$ de cada uma das análises realizadas.

Tabela 10 - Associação entre o consumo de drogas estimulantes e as variáveis coletadas através dos relatos dos caminhoneiros, com valores de $p$ e de chi-quadrado $\left(x^{2}\right)$, Estado de São Paulo, 2012.

\begin{tabular}{c|c|c|c}
\hline \hline Variáveis & $\boldsymbol{p}$ & $\boldsymbol{x}^{2}$ & $\begin{array}{c}\text { Associação } \\
\text { significativa }\end{array}$ \\
\hline Idade & $\mathbf{0 , 0 0 4 7}$ & $\mathbf{7 , 9 8 6}$ & Sim \\
\hline Tempo de profissão & 0,052 & 5,9154 & Não \\
\hline $\begin{array}{c}\text { Vínculo empregatício } \\
\text { Estado civil }\end{array}$ & 0,374 & 0,7917 & Não \\
\hline Etnia & $\mathbf{0 , 0 0 6}$ & $\mathbf{7 , 5 5 0 9}$ & Sim \\
\hline Escolaridade & 0,875 & 0,2679 & Não \\
\hline Número de ocupantes & 0,790 & 0,071 & Não \\
\hline Tipo de carga & 0,182 & 6,2356 & Não \\
\hline \hline
\end{tabular}

4.3.2 Associação do resultado da análise toxicológica com as variáveis relacionadas à viagem

As questões feitas aos caminhoneiros envolviam também características sobre a viagem (distância e tempo em horas) e sobre o tempo de descanso 
(diurno e noturno). As análises a seguir foram realizadas relacionando essas variáveis da viagem com o uso de substâncias psicoativas estimulantes.

\section{Distância}

A distância esteve diretamente associada ao consumo de drogas estimulantes $(p=0,0310)$. Os motoristas cujas urinas apresentaram resultado positivo na análise toxicológica tiveram média de distância percorrida de 1.178 quilômetros, com mediana de 1.200 (variando de 3 a 3.400). Já entre os casos negativos, a distância média percorrida pelos caminhoneiros foi de 679 quilômetros, com mediana de 320 (variando de 1 a 5.000).

\section{Tempo de descanso diurno}

Aos caminhoneiros foi perguntado qual era o tempo aproximado de descanso durante as paradas diurnas. As respostas variaram de 10 minutos até 3 horas, com média de 45 minutos, tanto para os casos positivos quanto para os negativos. Dessa forma, o tempo de descanso não esteve associado ao uso de drogas estimulantes $(p=0,7765)$.

\section{Tempo de descanso noturno}

Já quando perguntados quanto tempo, em média, costumavam descansar e dormir pela noite em viagens longas, os caminhoneiros que apresentaram resultado de análise toxicológica positivo relataram descansar por 5,5 horas em média, enquanto os que tiveram resultado negativo relataram descansar por 7 horas, em média. Essa diferença foi estatisticamente significante $(p=0,0384)$, 
indicando que o tempo de descanso esteve associado ao uso de drogas estimulantes.

\section{Tempo total da viagem}

Apesar da distância estar associada ao uso de drogas, o tempo de duração da viagem não apresentou diferença estatisticamente significante $(p=0,2824)$ quando avaliado o uso de substâncias estimulantes. A média de horas viajadas pelos caminhoneiros com resultado de análise toxicológica positivo e negativo foi de 41,7 e 23,3 horas, respectivamente.

\section{Tempo já viajado}

Outra questão feita aos motoristas era sobre o tempo já viajado desde o local de partida até o momento da coleta das amostras de dados e de urina. A relação deste tempo de viagem com o uso de drogas estimulantes também não mostrou diferença estatisticamente significante $(p=0,2353)$. Os motoristas com resultado de análise toxicológica positivo relataram estar viajando, em média, há 26,8 horas e aqueles com resultado negativo estavam viajando, em média, há 11,8 horas.

\section{Tempo direto na direção}

Quando perguntados quanto tempo, em média, os caminhoneiros costumavam dirigir sem uma parada para descanso, as respostas variaram de 30 minutos até 20 horas ininterruptas. Os motoristas com resultado de análise toxicológica positivo dirigiam por um período maior, em média 5,9 horas, enquanto os motoristas com resultado negativo relataram dirigir, em média, 4,6 
horas antes de cada parada para descanso. A análise destes resultados mostrou valor de $p$ bem próximo ao limite da significância estabelecida $(p=0,0510)$.

O resumo das variáveis relacionadas à viagem se encontra na Tabela 11, que traz os valores de médias e medianas para os casos positivos e negativos, assim como os valores de $p$ e do chi-quadrado $\left(x^{2}\right)$.

Tabela 11 - Amostras de urina de caminhoneiros segundo resultado toxicológico (negativo ou positivo para anfetamina e cocaína) e associações com as variáveis relacionadas à viagem coletadas através de relatos, com valores de média, mediana, amplitude, $p$ e chi-quadrado $\left(x^{2}\right)$, Estado de São Paulo, 2012.

\begin{tabular}{|c|c|c|c|c|c|c|}
\hline Drogas & Média & Mediana & Amplitude & $p$ & $x^{2}$ & $\begin{array}{l}\text { Associação } \\
\text { significativa }\end{array}$ \\
\hline \multicolumn{7}{|c|}{ Distância (km) } \\
\hline Positivo & 1.178 & 1200 & 3 a 3.400 & \multirow{2}{*}{0,0310} & \multirow{2}{*}{4,653} & \multirow{2}{*}{ Sim } \\
\hline Negativo & 679 & 320 & 1 a 5.000 & & & \\
\hline \multicolumn{7}{|c|}{ Tempo de descanso diurno (minutos) } \\
\hline Positivo & 45 & 30 & 30 a 90 & \multirow{2}{*}{0,7765} & \multirow{2}{*}{0,081} & \multirow{2}{*}{ Não } \\
\hline Negativo & 45 & 30 & 10 a 180 & & & \\
\hline \multicolumn{7}{|c|}{ Tempo de descanso noturno (horas) } \\
\hline Positivo & 5,5 & 5,5 & 0 a 10 & \multirow{2}{*}{0,0384} & \multirow{2}{*}{4,287} & \multirow{2}{*}{ Sim } \\
\hline Negativo & 7 & 8 & 0 a 13 & & & \\
\hline \multicolumn{7}{|c|}{ Tempo total da viagem (horas) } \\
\hline Positivo & 41,7 & 15 & 1 a 384 & \multirow{2}{*}{0,2824} & \multirow{2}{*}{1,156} & \multirow{2}{*}{ Não } \\
\hline Negativo & 23,3 & 6 & 1 a 192 & & & \\
\hline \multicolumn{7}{|c|}{ Tempo já viajado (horas) } \\
\hline Positivo & 26,8 & 4,5 & 0 a 288 & \multirow{2}{*}{0,2353} & \multirow{2}{*}{1,409} & \multirow{2}{*}{ Não } \\
\hline Negativo & 11,8 & 2 & 0 a 1.080 & & & \\
\hline \multicolumn{7}{|c|}{ Tempo direto na direção (horas) } \\
\hline Positivo & 5,9 & 4,7 & 3 a 16 & \multirow{2}{*}{0,0510} & \multirow{2}{*}{3,810} & \multirow{2}{*}{ Não } \\
\hline Negativo & 4,6 & 4 & 0,5 a 20 & & & \\
\hline
\end{tabular}




\subsubsection{Associação do resultado da análise toxicológica com}

\section{outras variáveis}

A respeito dos aspectos de saúde, os relatos indicaram ausência/presença de doenças e então foram associados com o uso de drogas estimulantes. Outras associações também foram pesquisadas com as respostas para questões sobre a prática de atividade física e padrão de consumo de álcool referido pelos motoristas.

Não houve associação entre o consumo de drogas estimulantes e a presença das doenças referidas: hipertensão arterial $(p=0,283)$, diabetes mellitus $(p=0,984)$ e estresse $(p=0,365)$.

A prática de atividades físicas e o consumo de drogas estimulantes também não estiveram associados $(p=0,986)$.

Já o consumo referido de álcool esteve associado ao consumo de drogas estimulantes $(p=0,005)$, como mostra a Tabela 12 .

Tabela 12 - Amostras de urina de caminhoneiros ( $\mathrm{N}$ e \%) segundo resultado toxicológico (negativo ou positivo para anfetamina e cocaína) distribuídas de acordo com o referido consumo ou não de álcool, Estado de São Paulo, 2012.

\begin{tabular}{c|cc|c}
\hline \hline Consumo de álcool & Positivos & Negativos & Total \\
\hline \hline \multirow{2}{*}{ Sim } & 20 & 238 & \\
& $7,7 \%$ & $92,3 \%$ & 258 \\
Não & 2 & 150 & \\
& $1,3 \%$ & $98,7 \%$ & 152 \\
\hline \hline TOTAL & 22 & 388 & 410 \\
\hline \hline
\end{tabular}




\section{DISCUSSÃO}

Diante do número crescente de mortes por AT no país e no mundo, cada vez mais estudos se fazem necessários na tentativa de identificar as principais causas desses acidentes para então ter subsídios para tentar minimizar sua ocorrência.

Estudos apontam que o fator humano é o principal responsável pela ocorrência desses acidentes ${ }^{17}$. Dessa forma, torna-se necessário estudar de modo aprofundado os fatores de risco relacionados especificamente ao condutor. Conhecer o perfil deste é importante para detectar a vulnerabilidade e razões pelas quais os acidentes acontecem para, assim, combatê-los e preveni-los ${ }^{16}$.

O consumo de álcool e outras drogas pelos condutores é um importante fator de risco para a ocorrência dos AT. Existem evidências científicas bem fundamentadas e amplamente aceitas da influência negativa do álcool e de outras substâncias psicoativas sobre a aptidão para conduzir e no aumento do risco de acidentes, assim como a gravidade de suas consequências. Entretanto, no Brasil esses estudos ainda são escassos, especialmente sobre o uso de drogas por motoristas ${ }^{19,27}$, o que incentivou a realização deste trabalho.

O Brasil possui o transporte de cargas rodoviário como o principal meio de deslocamento de suas mercadorias, correspondendo a $90 \%$ da demanda total de transportes ${ }^{53}$. Como consequência da grande frota de caminhões circulando nas estradas, os acidentes que envolvem esses veículos 
correspondem a $25 \%$ do total de acidentes ocorridos nas rodovias federais policiadas $^{49}$.

Devido à extensão do país e de suas estradas, os caminhoneiros que fazem esse tipo de transporte frequentemente se deparam com longas distâncias a serem percorridas, geralmente num curto prazo de tempo. Isso leva a um conjunto de fatores que pode aumentar as chances de ocorrência de AT como a sonolência decorrente de poucas horas de sono, horários irregulares de trabalho, viagens noturnas sem descanso, pressa em voltar para casa e consequente uso de substâncias psicoativas para manter o estado de

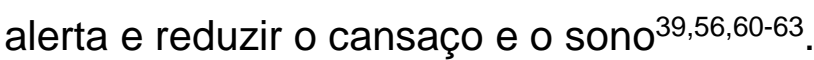

Neste estudo, optamos por estimar a prevalência de uso de anfetaminas, cocaína e cannabis por serem as drogas mais utilizadas pela população brasileira. Assim como em outros estudos epidemiológicos ${ }^{73,75,77-80}$, a urina foi escolhida para a análise toxicológica por ser uma matriz biológica de fácil coleta, que é realizada de forma não-invasiva.

A urina é uma matriz biológica que reflete o uso recente da substância pesquisada ${ }^{64}$. Por exemplo, a presença da benzoilecgonina na urina pode evidenciar o uso de cocaína num período de horas a dias antes da coleta da amostra, não significando necessariamente dizer que 0 motorista se encontrava sob a influência da droga quando foi abordado ${ }^{42}$. Como o objetivo deste trabalho foi verificar a prevalência de uso das drogas, a pesquisa na urina foi apropriada. Por outro lado, para fins de fiscalização, quando há intenção de flagrar o motorista na direção sob efeito da droga, as amostras biológicas indicadas seriam o sangue e o fluido oral, que refletem a concentração plasmática da droga. Dessa forma, a presença de cocaína, por 
exemplo, nessas matrizes pode ser interpretada como um forte indicativo que o motorista estava sob os efeitos farmacológicos da droga no instante da coleta $^{42}$.

Ainda em relação à coleta das amostras, obtivemos uma baixa taxa de recusa $(3,8 \%)$ por se tratar de um estudo anônimo e confidencial. $O$ fato das amostras e do questionário não terem sido identificados e também por estarem participando de uma ação voltada à promoção da saúde, incentivou os indivíduos a participarem. O caráter informal com que foram realizadas as perguntas pelos pesquisadores também ajudou na aceitação do participante.

Estudos de outros países sobre o uso de drogas por caminhoneiros, em sua maioria, mostram resultados com positividade para álcool e outras drogas. As porcentagens para uso de álcool ficam, em média, em torno dos $10 \%$. Já o uso de drogas tem prevalência distinta, dependendo do país e da metodologia de coleta e análise dos dados, que são diferentes em cada estudo, tornando inviável a comparação dos resultados entre eles ${ }^{65-67}$.

Já os estudos brasileiros sobre o uso de drogas por caminhoneiros são escassos e os existentes, apesar de apresentarem prevalências semelhantes entre si, as diferenças na metodologia do trabalho inviabilizam a comparação direta entre os resultados, pois a maioria é baseada somente em relato dos motoristas $^{39,68,69,71,74}$. Os estudos que referem análises toxicológicas mostraram que os motoristas fazem uso das mesmas drogas pesquisadas neste trabalho $42,73,75,78,80$. Apesar da dificuldade de analogia dos dados, os trabalhos existentes e os resultados obtidos nesta pesquisa são discutidos a seguir.

Todos os participantes da pesquisa eram homens, com idade média de 41 anos. A maioria $(74,5 \%)$ dos participantes era casada ou amasiada. Em 
relação à escolaridade e tempo de profissão, 60\% dos caminhoneiros tinham até 8 anos de estudo e a maioria (77\%) possuía mais de 5 anos de experiência. Perfis semelhantes foram encontrados em outros estudos brasileiros ${ }^{42,75,77-80}$.

A prevalência de $7,8 \%$ para o uso de drogas encontrada em nosso estudo é semelhante aos resultados descritos por outros autores em trabalhos recentes realizados no Brasil, de diversos estados e coletados em diferentes anos. Considerando que as metodologias dos estudos não são idênticas, os resultados compatíveis podem indicar que o consumo dessas drogas se faz presente a nível nacional e foi constante ao longo dos últimos anos.

Porém, existem alguns resultados bem diferentes, o que pode ser devido às metodologias distintas. Por exemplo, no trabalho realizado por Yonamine et al. ${ }^{72}$ os resultados toxicológicos foram bem mais baixos $(3,1 \%)$, provavelmente devido ao uso de fluido oral como matriz biológica para as análises toxicológicas, que tem uma janela de detecção inferior à da urina. As drogas pesquisadas e encontradas foram as mesmas, indicando que o uso destas entre 2002 e 2008 foi constante e continua sendo até os dias de hoje como mostram os estudos mais recentes. Outro exemplo são os trabalhos nos quais os resultados baseiam-se em relatos dos caminhoneiros $39,68,69,71,74$, que apresentam porcentagens mais altas como referido anteriormente.

Os estudos brasileiros que realizaram análise toxicológica em urina mostraram resultados positivos para as mesmas drogas pesquisadas neste estudo ${ }^{73,75,77-80}$

Os estudos de Takitane et al. (2012) ${ }^{77}$ e Oliveira et al. (2013) $)^{79}$ tiveram como objetivo verificar o uso apenas de anfetamina entre os caminhoneiros e, portanto, não contemplaram as prevalências de outras drogas. Os outros 
trabalhos ${ }^{73,75,80}$, uma vez que utilizaram de metodologias bem parecidas como a aplicada neste estudo, trazem prevalências de uso das drogas bem semelhantes, com a anfetamina como droga mais utilizada, exceto Peixe et al. $(2014)^{78}$ que mostraram a cocaína como droga mais usada. Os autores inferem que a restrição do comércio legal de anfetaminas devido à implementação da RDC № $52 / 2011^{40}$ da ANVISA, pode ter levado os caminhoneiros a procurarem outras substâncias estimulantes, como a cocaína, que é uma droga facilmente encontrada, o que pode também estimular seu consumo.

O crescimento do número de motoristas que fizeram uso da cocaína foi observado no presente estudo e podemos inferir que esse aumento ocorreu, provavelmente, em consequência da implementação da RDC referida anteriormente, que proibiu a produção e venda de derivados anfetamínicos. A cocaína teve maiores prevalências de uso encontradas em períodos posteriores à implementação dessa resolução. Apesar de ser divulgado pela mídia o comércio de drogas nas estradas e o uso de cocaína por caminhoneiros no país, mais estudos devem ser elaborados para que seja comprovado esse fato. Os trabalhos que descreveram os relatos dos caminhoneiros mostram que o uso da cocaína se dá pelos mesmos motivos do uso do rebite, ou seja, para ficarem acordados para cumprir seus prazos de entrega ${ }^{52}$.

Apesar de termos observado uma queda no uso das anfetaminas, ainda foram encontradas amostras de urina que apresentaram resultados positivos para a droga em períodos posteriores à sua proibição. Isso pode ter ocorrido pela disponibilidade dos medicamentos à base de anfetamina comercializados de forma ilegal, conforme relato informal dos motoristas à equipe de coleta. 
Oliveira et al., em $2013^{79}$, mostraram que a despeito da implementação da $\mathrm{RDC}^{40}$, o uso de anfetaminas continuou vigente entre motoristas de caminhão, possivelmente com a mesma magnitude de antes. Os autores sugeriram então que fosse fiscalizada a posse e o uso dessas drogas no contexto do trânsito.

A baixa prevalência do uso de cannabis encontrada neste e em outros estudos $^{73,75,80}$ pode indicar que esta droga não é utilizada para fins laborais. Como os principais objetivos dos caminhoneiros são reduzir a fadiga e manterse acordados por muitas horas, eles buscam substâncias estimulantes para tal finalidade. A cannabis, como é uma droga perturbadora, não traz os efeitos estimulantes desejados e provavelmente pode estar associada apenas a uso recreativo dos motoristas. Foi encontrada em todos os anos de estudo, exceto em 2008, provavelmente porque o número de amostras coletadas neste ano foi bem reduzido em relação aos outros anos por se tratar do período inicial da pesquisa. No estudo de Peixe et al. ${ }^{78}$ também não foram encontrados casos positivos para cannabis e o motivo pode ter sido o mesmo, a baixa amostragem no estudo.

Como exposto nas seções métodos e resultados deste trabalho, a análise estatística para pesquisar a associação das variáveis coletadas no questionário com o uso de drogas foram realizadas utilizando-se apenas os dados do ano de $2012(n=410)$. Como os resultados deste ano refletem os achados dos anos anteriores, o corte facilitou os cálculos estatísticos além de oferecer dados mais recentes sobre o uso de drogas e as associações com as variáveis disponíveis para análise, que serão discutidas a seguir. Como citado anteriormente, a cannabis não está relacionada às atividades laborais, portanto, para a busca de 
associação do uso de drogas com as variáveis, foram consideradas somente as amostras que apresentaram resultado positivo para drogas estimulantes: anfetaminas e cocaína.

Os resultados mostraram que houve associação significativa do uso de drogas estimulantes com a idade do motorista e com o estado civil.

Entre os motoristas mais jovens houve um maior consumo de drogas estimulantes, indicando que os motoristas mais velhos, e consequentemente, com mais tempo de experiência profissional são mais cautelosos quanto à segurança no trânsito. Podemos inferir tal hipótese, pois a variável 'tempo de experiência profissional' não apresentou associação estatisticamente significante, mas apresentou valor de $p$ muito próximo ao limite da significância estabelecida $(p=0,052)$.

O estado civil esteve associado ao uso de drogas estimulantes pelos caminhoneiros. No estudo, foi encontrado menor frequencia de uso de drogas por motoristas casados/amasiados do que entre os solteiros/viúvos, tanto no resultado da análise toxicológica, quanto nas respostas aos questionários. Assim, podemos inferir que dentre os motoristas que vivem sozinhos há maiores frequências de uso de drogas nas estradas, pois aqueles que possuem uma companheira se preocupam mais com a segurança na viagem e dirigem com mais responsabilidade.

O uso de drogas estimulantes se distribuiu de forma diferente entre os motoristas autônomos e os contratados por empresas, porém sem apresentar diferença estatisticamente significante. Dentre os motoristas que referiram ser autônomos, a frequência de uso de drogas estimulantes foi menor, indicando possivelmente, que a pressão que as empresas exercem em seus funcionários 
com relação a prazos curtos para entrega de mercadorias, possa incentivar o uso de drogas estimulantes por esses profissionais. Já os autônomos contam com uma flexibilidade um pouco maior nos horários e tem a opção de prolongar os prazos de entregas quando necessário, segundo relatam os motoristas e assim, necessitam recorrer menos ao uso de estimulantes para se manterem acordados.

Por outro lado, apesar da porcentagem do uso de estimulantes pelos contratados ter sido mais alta, muitos deles vêm relatando nos últimos anos que dirigem caminhões rastreados e são impedidos de dirigir à noite, sendo assim, obrigados a fazer paradas para descanso noturno. Além disso, essas empresas exigem e fiscalizam as paradas para descanso diurno obrigatórias, seguindo o estabelecido pela Lei № 12.619 de 30 de abril de 2012, também conhecida como Lei do Descanso ${ }^{86}$. A lei exige que em viagens de longas distâncias (quando o motorista permanece mais de 24 horas em viagem), a cada 4 horas de tempo ininterrupto de direção os motoristas realizem intervalo mínimo de 30 minutos. Além disso, a lei assegura aos caminhoneiros intervalo mínimo de 1 hora para refeição, além de intervalo de repouso diário de 11 horas a cada 24 horas. Se cumprissem fielmente o descrito na lei, os motoristas relatam que não teriam a necessidade de procurar substâncias estimulantes para dirigir. Porém, a iniciativa de obedecer a legislação e fiscalizar seus motoristas é adotada apenas por algumas empresas. Se todas as companhias que utilizam transporte de cargas de longas distâncias se comprometessem a fazer o mesmo, isso certamente ajudaria no aumento da segurança nas estradas e no combate à ocorrência de AT. Soma-se a isso, o benefício de diminuição dos prejuízos que tem a própria empresa com os 
acidentes que podem ocorrem em virtude de privação de sono dos motoristas e consequente uso de drogas.

As variáveis etnia e nível de escolaridade não apresentaram associações significativas com o uso de drogas estimulantes, apesar deste ter se demonstrado diferente conforme o tempo de estudo dos caminhoneiros. Aqueles com tempo de estudo de até 8 anos (ensino fundamental completo) tiveram prevalência de uso superior aos mais escolarizados (ensino médio completo) e dentre os que possuíam ensino superior não foi identificado o uso de drogas. Esses dados podem indicar que, possivelmente, quanto maior 0 grau de instrução do caminhoneiro, maior é o discernimento dele em relação à segurança na direção e o uso de drogas. O número de ocupantes e o tipo de carga também não apresentaram associação significativa com a positividade encontrada na análise toxicológica.

Já em relação à viagem, as associações do uso de drogas estimulantes não foram encontradas nas seguintes variáveis: tempo de descanso diurno, tempo total da viagem, tempo já viajado e horas corridas na direção sem parada para descanso. Talvez pelo fato de que estas variáveis mudem conforme a necessidade da viagem em curso do caminhoneiro (ora ele descansa mais, ora descansa menos), não puderam ser associadas com o uso de drogas estimulantes. A média de 4,6 horas ininterruptas na direção foi semelhante à encontrada no estudo de Oliveira et al. ${ }^{79}$, de 4,7 horas.

Porém, apesar de também variarem de acordo com a viagem em curso, o tempo de descanso noturno habitual e a distância da viagem estiveram relacionados com 0 uso de drogas estimulantes, com diferenças estatisticamente significantes. 
Esses resultados quanto ao tempo médio de descanso noturno dos motoristas são consistentes com os achados de Nascimento et al. (2005) ${ }^{39}$ que mostraram que a maioria dos entrevistados disse preferir viajar no período noturno ou nas madrugadas e relatou dormir menos de 6 horas por noite. 0 estudo comprovou a associação do período de trafegar com o uso de anfetamina. Nossos resultados mostraram que os motoristas que fizeram uso de drogas estimulantes relataram descansar em média 5,5 horas pela noite, enquanto os caminhoneiros que não usaram drogas relataram descansar em média 7 horas.

A respeito da distância e o uso de drogas estimulantes, outros trabalhos $^{74,80}$ também discutiram essa associação, corroborando nossos resultados. No estudo de Sinagawa et al. ${ }^{80}$ foi inferido que quanto maior era a distância percorrida, maior foi a prevalência de consumo de anfetaminas. Motoristas que estavam em viagens mais longas que 270 quilômetros fizeram uso de anfetaminas em maior porcentagem do que aqueles que percorreram percursos menores. No presente estudo, os motoristas que fizeram uso de estimulantes, ou seja, cujas análises toxicológicas foram positivas para as drogas estudadas, percorreram distâncias mais longas, com viagens com distância média de 1.178 quilômetros, enquanto os motoristas que não usaram drogas estavam em viagens mais curtas, com média de 679 quilômetros.

Por fim, não foi encontrada diferença estatisticamente significante entre o uso de drogas estimulantes e a prática de atividades físicas ou problemas de saúde referidos pelos motoristas. Essa associação foi encontrada em relação ao consumo de álcool, segundo relatos dos caminhoneiros. Não foi realizada a análise toxicológica para verificar a presença de álcool na urina, pois não era o 
objetivo do estudo. A positividade para drogas estimulantes encontrada dentre os motoristas que habitualmente ingerem bebidas alcoólicas (independentemente da frequência) foi muito superior àquela encontrada dentre os abstêmios, segundo informações obtidas nos questionários.

Em suma, o uso de drogas por caminhoneiros além de trazer prejuízos pessoais, como na saúde do próprio condutor, também acarretam desdobramentos negativos para a sociedade em geral como diminuição na segurança nas estradas e custos oriundos de possíveis acontecimentos de AT, uma vez que o consumo de drogas está associado com a ocorrência desses acidentes $^{32}$. Dessa forma, consideramos que os resultados deste estudo possam contribuir para um melhor conhecimento sobre o uso de drogas nas estradas e possam servir como base para a idealização de políticas públicas que ajudem a melhorar a segurança no trânsito, objetivando a prevenção dos acidentes. São necessárias iniciativas que envolvam modificações na legislação para uma futura regulamentação da jornada de trabalho destes profissionais na tentativa de diminuir o consumo de substâncias estimulantes e consequentemente, o risco de AT. 


\section{CONCLUSÕES}

- Entre os anos de 2008 a 2012 foi frequente o uso de anfetaminas, cocaína e cannabis por motoristas de caminhão que trafegavam nas rodovias do Estado de São Paulo com prevalência estimada de uso de 7,8\%;

- Dentre o total de amostras coletadas, 3,4\% apresentaram resultado positivo para anfetaminas, 2,8\% para benzoilecgonina (metabólito da cocaína), 1,1\% para THC-COOH (metabólito do THC, princípio ativo da cannabis) e 0,5\% para uso múltiplo de drogas;

- Perfil sociodemográfico: todos homens, com idade média de 41 anos. Maioria brancos $(93,5 \%)$, casados $(74,5 \%)$, com ensino fundamental completo $(60,7 \%)$, mais de 5 anos de experiência profissional $(77,3 \%)$ e contratados por empresas $(62,7 \%)$;

- A análise do ano de 2012 mostrou que o uso de drogas estimulantes esteve associado com a idade do caminhoneiro, o estado civil e o consumo referido de álcool. Em relação à viagem, o uso de drogas se associou à distância percorrida e o tempo de descanso noturno;

- A análise do ano de 2012 mostrou que o uso de drogas estimulantes não esteve associado às seguintes variáveis: vínculo empregatício, tempo de profissão, etnia, escolaridade, número de ocupantes no caminhão, tipos de carga, tempo de descanso diurno, tempo total da viagem, horas já viajadas e tempo na direção. Também não esteve associado à presença de hipertensão arterial, diabetes mellitus, estresse e prática de atividades físicas. 


\section{REFERÊNCIAS BIBLIOGRÁFICAS}

1. Departamento Nacional de Infraestrutura de Transportes e Departamento de Polícia Rodoviária Federal. Anuário estatístico das Rodovias Federais - Acidentes de Trânsito e Ações de Enfrentamento ao Crime. Brasília: DNIT/ DPRF; 2010.

2. Brasil. Ministério da Saúde. Sistema de Informações sobre Mortalidade (SIM). O Sistema de Informações sobre Mortalidade. Brasília (DF): Ministério da Saúde; 1995.

3. Brasil. Ministério da Saúde. Secretaria de Vigilância em Saúde. Departamento de Análise de Situação em Saúde. Saúde Brasil 2010: uma análise da situação de saúde e de evidências selecionadas de impacto de ações de vigilância em saúde. Estatística e Informação em Saúde. Brasília (DF): Ministério da Saúde; 2011.

4. Organização Mundial da Saúde. Classificação estatística internacional de doenças e problemas relacionados à saúde. São Paulo: Edusp; 1995.

5. World Health Organization. Global status report on road safety 2013: supporting a decade of action. Geneva: WHO; 2013.

6. Brasil. Ministério da Saúde. Sistema de Informações sobre Mortalidade (SIM). Coordenação Geral de Informações e Análise Epidemiológica (CGIAE). Consolidação da base de dados de 2011. Brasília (DF): Ministério da Saúde; 2011.

7. Mello Jorge MHP, Koizumi MS. Gastos governamentais do SUS com internações hospitalares por causas externas: análise no Estado de São Paulo, 2000. Rev. Bras. Epidemiol. 2004; 7(2): 228-238.

8. Banco de Dados do Sistema Único de Saúde. Informações de Saúde Relatório 2010. Brasília: DATASUS/Ministério da Saúde; 2010.

9. Banco de Dados do Sistema Único de Saúde. Informações de Saúde Epidemiológica e Morbidade. Brasília: DATASUS/Ministério da Saúde; 2011.

10. Waiselfisz, JJ. Mapa da Violência 2012. Os novos padrões da violência homicida no Brasil. São Paulo: Instituto Sangari; 2012.

11. Waiselfisz, JJ. Mapa da Violência 2013. Acidentes de trânsito e motocicletas. Rio de Janeiro: CEBELA (Centro Brasileiro de Estudos Latino-Americanos); 2013. 
12. Associação Brasileira de Medicina do Tráfego (ABRAMET). Acidentes de trânsito no Brasil: um atlas de sua distribuição. 2a ed. São Paulo: ABRAMET; 2013.

13. Mello Jorge MHP, Latorre MRDO. Acidentes de trânsito no Brasil: Dados e tendências. Cad. Saúde Pública. 1994; 10(1):19-44.

14. Instituto de Pesquisa Econômica e Aplicada/Associação Nacional de Transportes Públicos). Impactos sociais e econômicos dos acidentes de trânsito nas aglomerações urbanas brasileiras. Relatório Executivo. Brasília: IPEA/ANTP; 2003.

15. Instituto de Pesquisa Econômica e Aplicada/Departamento Nacional de Trânsito/Associação Nacional de Transportes Públicos. Impactos sociais e econômicos dos acidentes de trânsito nas rodovias brasileiras. Relatório Executivo. Brasília: IPEA/DENATRAN/ANTP; 2006.

16. Mello Jorge MHP, Koizumi MS. Sequelas visíveis de acidentes de trânsito: primeiros dados brasileiros. Rev ABRAMET. 2012; 29(1): 36-45.

17. Departamento Nacional de Infraestrutura de Transportes e Universidade Federal de Santa Catarina. Dados de boletim de ocorrência. Implementação do núcleo de estudos sobre acidentes de tráfego em rodovias - ficha técnica. Brasília: DNIT/UFSC; 2008.

18. Marin L, Queiroz MS. A atualidade dos acidentes de trânsito na era da velocidade: uma visão geral. Cad. Saúde Pública. 2000; 16(1): 7-21.

19. Organización Mundial de la Salud. Accidentes del tráfico en los países en desarrollo. Ginebra: OMS; 1984.

20. Oliveira LG, Yonamine M, Andreuccetti G, Ponce JC, Leyton V. Alcohol and other drug use by Brazilian truck drivers: a cause for concern? Rev Bras Psiquiatr. 2012; 34:116-7.

21. Brasil. Ministério da Saúde/Secretaria de Vigilância em Saúde. VIGITEL Brasil 2013: vigilância de fatores de risco e proteção para doenças crônicas por inquérito telefônico - Estimativas sobre frequência e distribuição sociodemográfica de fatores de risco e proteção para doenças crônicas nas capitais dos 26 estados brasileiros e no Distrito Federal em 2013. Brasília (DF): Ministério da Saúde; 2014.

22. Secretaria Nacional de Políticas sobre Drogas. Glossário de álcool e drogas. Brasília: SENAD; 2010.

23. United Nations Office for Drug Control and Crime Prevention. World Drug Report. Nova lorque: UNODC; 2014. 
24. United Nations Office for Drug Control and Crime Prevention. World Drug Report. Nova lorque: UNODC; 2011.

25. Carlini EA, supervisão. I/ Levantamento Domiciliar sobre o uso de Drogas Psicotrópicas no Brasil: estudo envolvendo as 108 maiores cidades do país - 2005. São Paulo: CEBRID; 2007.

26. Instituto Nacional de Ciência e Tecnologia para Políticas Públicas de Álcool e Outras Drogas (INPAD)/ Laranjeira R, supervisão. II Levantamento Nacional de Álcool e Drogas (LENAD). São Paulo: UNIFESP; 2014.

27. Ponce JC, Leyton V. Drogas ilícitas e trânsito: problema pouco discutido no Brasil. Rev Psiquiatr Clín. 2008; 35: 65-9.

28. Gates J, Dubois S, Mullen N, Weaver B, Be M. The influence of stimulants on truck driver crash responsibility in fatal crashes. Forensic Sci Int. 2013; 228:15-20.

29. Drummer $\mathrm{OH}$, Gerostamoulos J, Batziris $\mathrm{H}$, Chu M, Caplehorn JRM, Robertson MD, et al. The incidence of drugs in drivers killed in Australian road traffic crashes. Forensic Sci Int. 2003; 134(2-3): 154-162.

30. Drummer OH, Gerostamoulos D, Chu M, Swann P, Boorman M, Cairns I. Drugs in oral fluid in randomly selected drivers. Forensic Sci Int. 2007; 170: 105-10.

31. Pechansky F, Duarte PCAV, De Boni R, organizadores. Uso de bebidas alcoólicas e outras drogas nas rodovias brasileiras e outros estudos. Porto Alegre: Secretaria Nacional de Políticas sobre Drogas; 2010.

32. Associação Brasileira de Medicina de Tráfego/Leyton V, Ponce JC, Montal JHC, Adura FE, participantes. Efeito do Uso de Drogas (Cannabis, Anfetaminas, Cocaína, Opiáceos e Alucinógenos) sobre 0 Comportamento e a Cognição de Motoristas. In: Associação Médica Brasileira (AMB). Projeto Diretrizes. São Paulo: AMB; 2012.

33. Larini L. Toxicologia. São Paulo: Mariole; 1995.

34. Silva P. Farmacologia. 7a ed. Rio de Janeiro: Guanabara Koogan; 2006.

35. Howland RD, Mycek MJ. Farmacologia Ilustrada. 3a ed. Porto Alegre: Artmed; 2007.

36. Transportation Research Board. Transportation Research Circular E-C096 - Drugs and traffic: a Symposium. Massachusetts, EUA: TRB; 2006. 
37. Silber BY, Papafotiou K, Croft RJ, Ogden E, Swann P, Stough C. The effects of dexamphetamine on simulated driving performance. Psychopharmacology (Berl). 2005; 179:536-43.

38. Stough C, Downey LA, King R, Papafotiou K, Swann P, Ogden E. The acute effects of 3,4-methylenedioxymethamphetamine and methanfetamine on driving: a simulator study. Accid Anal Prev. 2012; 45:493-7.

39. Nascimento EC, Nascimento E, Silva JdeP. Alcohol and amphetamines use among long distance truck drivers. Rev Saúde Pública. 2007; 41(2): 290-3.

40. Brasil. ANVISA. Resolução no 52, de 6 de outubro de 2011. Dispõe sobre a proibição do uso das substâncias anfepramona, femproporex e mazindol, seus sais e isômeros, bem como intermediários e medidas de controle da prescrição e dispensação de medicamentos que contenham a substância sibutramina, seus sais e isômeros, bem como intermediários. Diário Oficial da União, Brasília (DF). 20116 out.

41. World Health Organization. Neuroscience of psychoactive substance use and dependence. Geneva: WHO; 2004.

42. Yonamine M. A saliva como espécime biológico para monitorar o uso de álcool, anfetamina, metanfetamina, cocaína e maconha por motoristas profissionais [tese]. São Paulo: Faculdade de Ciências Farmacêuticas, Universidade de São Paulo; 2004.

43. Stoduto G, Mann RE, lalomiteanu A, Wickens CM, Brands B. Examining the link between collision involvement and cocaine use. Drug Alcohol Depend. 2012; 123: 260-3.

44. Ramaekers JG, Berghaus G, van Laar M, Drummer OH. Dose related risk of motor vehicle crashes after cannabis use. Drug Alcohol Depend. 2004; 73:109-19.

45. Fergusson DM, Horwood LJ. Cannabis use and traffic accidents in a birth cohort of young adults. Accid Anal Prev. 2001; 33:703-11.

46. Drummer $\mathrm{OH}$, Gerostamoulos J, Batziris H, Chu M, Caplehorn J, Robertson $\mathrm{D}$ et al. The involvement of drugs in drivers of motor vehicles killed in Australian road traffic crashes. Accid Anal Prev. 2004; 36:239-48.

47. Departamento Nacional de Infraestrutura de Transportes. Planejamento e programação de investimentos. Evolução da malha rodoviária. Brasília: DNIT; 2013.

48. Banco de Dados do Sistema Único de Saúde. Óbitos por causas externas. Brasília: DATASUS - Ministério da Saúde; 2011. 
49. Departamento Nacional de Infraestrutura de Transportes e Departamento de Polícia Rodoviária Federal. Anuário estatístico das Rodovias Federais - Acidentes de Trânsito e Ações de Enfrentamento ao Crime. Brasília: DNIT/ DPRF; 2010.

50. Departamento Nacional de Trânsito. Frota de veículos, por tipo e com placa, segundo as Grandes Regiões e Unidades de Federação. Brasília: DENATRAN; 2013.

51. Ministério dos Transportes. Anuário estatístico dos transportes terrestres. Brasília: ANTT; 2007.

52. Silva LG. O trabalho dos motoristas de caminhão: a relação entre atividade, vínculo empregatício e acidentes de trabalho [dissertação]. São Paulo: Faculdade de Saúde Pública, Universidade de São Paulo; 2011.

53. Secretaria dos Transportes e Agência de Transporte do Estado de São Paulo. Pesquisa de origem e destino do transporte rodoviário e aéreo do Estado de São Paulo - Relatório Executivo. São Paulo: ARTESP; 2006.

54. Heinrich JSS. Aplicação da análise de riscos a atividades do transporte rodoviário de carga geral [dissertação]. São Paulo: Faculdade de Engenharia Civil, Arquitetura e Urbanismo, Universidade Estadual de Campinas; 2004.

55. Agência Nacional de Transportes Terrestres. Relatório Anual 2011. Brasília: ANTT; 2012.

56. Moreno CRC, Fischer FM, Rotenberg L. As jornadas de trabalho dos motoristas profissionais. In: Mello MT de, Bittencourt LR, Pires MLN, Silva $\mathrm{RS}$ da, Tufik S (Org.). Sono: aspectos profissionais e suas interfaces com a saúde. São Paulo: Atheneu, 2007, v. 1, p. 1-13.

57. Moreno CRC, Matuzaki L, Carvalho F, Alves R, Pasqua I, Lorenzi Filho G. Truck Drivers Sleep-Wake Time Arrangements. Biol Rhythm Res. 2003; 34(2): 137-143.

58. Moreno CRC, Pasqua IC, Cristofoletti IMF. Turnos irregulares de trabalho e sua influência nos hábitos alimentares e de sono: o caso dos motoristas de caminhão. Rev ABRAMET. 2001; 36: 7-24.

59. Penteado RZ, Gonçalves CGO, Costa DD, Marques JM. Trabalho e saúde em motoristas de caminhão no interior de São Paulo. Saúde Soc. 2008; 17(4): 1-16.

60. Resende PTV, Sousa PR, Silva JVR. Fontes de tensão e estresse nos caminhoneiros brasileiros: uma análise a partir do modelo occupational stress indicator. In: Simpósio de Administração da Produção, Logística e Operações internacionais (SIMPOI, XIII) FGV - EAESP, 2010 p. 1-17. 
61. Veronese AM, Oliveira DLLC. Os riscos dos acidentes de trânsito na perspectiva dos motoboys: subsídios para a promoção da saúde. Cad. Saúde Pública. 2006; 22(12): 2717-21.

62. Sena MFM. As condições e causas dos acidentes de trabalho dos caminhoneiros [dissertação]. Rio de Janeiro: Ciências em Engenharia de Produção, Universidade Federal do Rio de Janeiro; 2005.

63. Maeno SW, Jorge AB, Leyton V, Andreuccetti G, Adura F, Strombech MLSC et al. Uso de "rebites" por motoristas de caminhão. In: Anais do VII Congresso Brasileiro e V Latino Americano sobre Acidentes e Medicina do Tráfego. 2007. Porto Seguro, Brasil.

64. Gjerde H, Øiestad EL, Christophersen AS. Using biological samples in epidemiological research on drugs of abuse. Norsk Epidemiologi. 2011; 21(1): 5-14.

65. Crouch DJ, Birky MM, Gust SW, Rollins DE, Walsh JM, Moulden JV, Quinlan KE, Beckel RW. The prevalence of drugs and alcohol in fatally injured truck drivers. J Forensic Sci. 1993; 38(6):1342-53.

66. Labat L, Fontaine B, Delzenne C, Doublet A, Marek MC, Tellier D, Tonneau $M$, Lhermitte $M$, Frimat $P$. Prevalence of psychoactive substances in truck drivers in the Nord-Pas-de-Calais region (France). Forensic Sci Int. 2008; 174:90-4.

67. Gjerde H, Christophersen AS, Normann PT, Pettersen BS, Sabaredzovic A, Samuelsen SO, Mørland J. Analysis of Alcohol and Drugs in Oral Fluid from Truck Drivers in Norway. Traffic Inj Prev. 2012; 13(1): 43-8.

68. Zeferino MT. Acidentes de trânsito e os estimulantes do tipo anfetaminas - Estudo de caso junto às empresas de transporte rodoviário de cargas no Estado de Santa Catarina [dissertação]. Florianópolis: Faculdade de Engenharia Civil, Universidade Federal de Santa Catarina; 2004.

69. Silva-Júnior FP, De Pinho RS, De Mello MT, De Bruin VM, De Bruin PF. Risk factors for depression in truck drivers. Soc Psychiatry Psychiatr Epidemiol. 2009; 44(2):125-9.

70. Leyton V, Carvalho DG, Jesus MGS, Muñoz DR. Uso de anfetamínicos por motoristas profissionais brasileiros: aspectos gerais. Saúde, Ética \& Justiça. 2000-2002; 5/7(1-2):32-6.

71. Villarinho L, Bezerra I, Lacerda R, Latorre MRO, Paiva V, Stall R, Hearst N. Caminhoneiros de rota curta e sua vulnerabilidade ao HIV. Rev Saúde Pública. 2002; 36(4): 61-7.

72. Yonamine M, Sanches LR, Paranhos BAPB, Almeida RM, Andreuccetti G, Leyton V. Detecting alcohol and illicit drugs in oral fluid samples collected 
from truck drivers in the state of São Paulo, Brazil. Traffic Inj Prev. 2013; $14: 127-31$.

73. Silva OA, Greve JMD, Yonamine M, Leyton V. Drug use by truck drivers in Brazil. Drugs Educ Prev Pol. 2003; 10(2):135-9.

74. Knauth DR, Leal AF, Pilecco FB, Seffner F, Teixeira AMF. Staying awake: truck drivers' vulnerability in Rio Grande do Sul, Southearn Brazil. Rev Saúde Pública. 2012; 46(5): 886-93.

75. Leyton V, Sinagawa DM, Oliveira KCBG, Schmitz W, Andreuccetti G, De Martins BS, Yonamine M, Muñoz DR. Amphetamine, cocaine and cannabinoids use among truck drivers on the roads in the State of Sao Paulo, Brazil. Forensic Sci Int. 2012; 215:25-7.

76. Moreira RS, Gadani JAAB. A prevalência do uso de anfetaminas por caminhoneiros que passam pela cidade de Dourados - MS. Interbio. 2009; 3(2): 27-34.

77. Takitane J, Oliveira LG, Endo LG, Oliveira KCBG, Muñoz DR, Yonamine $M$, Leyton V. Uso de anfetaminas por motoristas de caminhão em rodovias do Estado de São Paulo: um risco à ocorrência de acidentes de trânsito? Cien Saude Colet. 2013; 18(5):1247-1254.

78. Peixe TS, de Almeida RM, Girotto E, de Andrade SM, Mesas AE. Use of illicit drugs by truck drivers arriving at Paranaguá port terminal, Brazil. Traffic Inj Prev. 2014; 15(7): 673-677.

79. Oliveira LG, Endo LG, Sinagawa DM, Yonamine M, Muñoz DR, Leyton V. A continuidade do uso de anfetaminas por motoristas de caminhão no Estado de São Paulo, Brasil, a despeito da proibição de sua produção, prescrição e uso. Cad. Saúde Pública. 2013; 29(9):1903-1909.

80. Sinagawa DM, Carvalho HB, Andreuccetti G, Prado NV, Oliveira KCBG, Yonamine M, Muñoz DR, Gjerde H, Leyton V. Association Between Travel Length and Drug Use Among Brazilian Truck Drivers. Traffic Inj Prev. 2015; 16(1): 5-9.

81. Catania JA, Kegeles SM, Coates TJ. Towards an understanding of risk behavior: an AIDS risk reduction model (ARRM). Health Educ Q. 1990; 17(1):53-72.

82. Yonamine M, Silva OA. Confirmation of cocaine exposure by gas chromatography-mass spectrometry of urine extracts after methylation of benzoylecgonine. J Chromatogr B Analyt Technol Biomed Life Sci. 2002; 773(1): 83-7.

83. Yonamine M, Tawil N, Moreau RLM, Silva OA. Solidphase microextraction-gas chromatography-mass spectrometry and headspace-gas 
chromatography of tetrahydrocannabinol, amphetamine, methamphetamine, cocaine and ethanol in saliva samples. J Chromatogr B Analyt Technol Biomed Life Sci. 2003; 789: 73-8.

84. Bush DM. The U.S. Mandatory Guidelines for Federal Workplace Drug Testing Programs: current status and future considerations. Forensic Sci Int. 2008; 174: 111-9.

85. Brasil. Conselho Nacional de Saúde. Resolução n. 196/96 de 10 de outubro de 1996 (versão 2012). Dispõe sobre as diretrizes e normas regulamentadoras de pesquisas envolvendo seres humanos. Diário Oficial da União, Brasília (DF). 199616 out.: 21.082-21.085.

86. Brasil. Presidência da República/Casa Civil. Lei no 12.619 , de 30 de abril de 2012. Dispõe sobre o exercício da profissão de motorista; altera a Consolidação das Leis do Trabalho - CLT, aprovada pelo Decreto-Lei no 5.452 , de $1^{\circ}$ de maio de 1943 , e as Leis №s 9.503, de 23 de setembro de 1997, 10.233, de 5 de junho de 2001, 11.079, de 30 de dezembro de 2004, e 12.023, de 27 de agosto de 2009, para regular e disciplinar a jornada de trabalho e o tempo de direção do motorista profissional; e dá outras providências. Diário Oficial da União, Brasília (DF). 20122 maio. 
ANEXO 1 - Termo de Consentimento Livre e Esclarecido (frente)

Faculdade de Medicina da Universidade de São Paulo

Departamento de Medicina Legal, Ética Médica e Medicina Social e do Trabalho

TERMO DE CONSENTIMENTO LIVRE E ESCLARECIDO

\section{I - DADOS DE IDENTIFICAÇÃO DO SUJEITO DA PESQUISA}

Nome:

Documento de Identidade:

Sexo: ( ) M

( ) F

Data de nascimento:

Endereço:

$\mathrm{N}^{\circ}$ :

Apt:

Bairro:

Cidade:

CEP:

Telefone:

\section{II - DADOS SOBRE A PESQUISA CIENTÍFICA}

1. TÍTULO DO PROTOCOLO DE PESQUISA:

Uso de substâncias psicoativas por motoristas profissionais

PESQUISADORA: Profa. Dra. Vilma Leyton

CARGO/FUNÇÃO: Professora Doutora

INSCRIÇÃO NO CONSELHO REGIONAL Nº 6.108

UNIDADE DO HCFMUSP: Departamento de Medicina Legal, Ética Médica e Medicina Social e do Trabalho

2.AVALIAÇÃO DO RISCO DA PESQUISA

$\begin{array}{lll}\text { Sem Risco ( ) } & \text { Risco Mínimo ( } x) & \text { Risco Médio ( ) } \\ \text { Risco Baixo ( ) } & \text { Risco Alto ( ) } & \\ \text { 3. DURAÇÃO DA PESQUISA: } 12 \text { meses } & \end{array}$

\section{III - REGISTRO DAS EXPLICAÇÕES DO PESQUISADOR AO SUJEITO DA PESQUISA SOBRE A PESQUISA}

1. Justificativa e os objetivos da pesquisa; 2. procedimentos que serão utilizados e propósitos, incluindo a identificação dos procedimentos; 3 . desconfortos e riscos esperados; 4 . benefícios que poderão ser obtidos.

1. Esta pesquisa está sendo feita para avaliar o quanto os motoristas profissionais têm utilizado substância psicoativas, principalmente os "rebites", e 
ANEXO 1 - Termo de Consentimento Livre e Esclarecido (verso)

explicar os riscos que essas substâncias podem acometer ao motorista e à sociedade como um todo.

2. O senhor (a) deverá responder a um questionário.

3. Será coletada uma amostra de urina.

4. O senhor (a) não será identificado (a).

5. Estamos coletando apenas informações sobre sua profissão e saúde (dados obtidos do questionário)

6. Mesmo que seu exame toxicológico seja positivo, o senhor (a) não será identificado (a) de forma nenhuma.

7. Não há desconfortos para a coleta de urina e os riscos dessa pesquisa são mínimos.

8. Os benefícios deste tipo de pesquisa é ajudar a implantar políticas para um trânsito mais seguro.

\section{ESCLARECIMENTOS DADOS PELO PESQUISADOR SOBRE GARANTIAS DO SUJEITO DA PESQUISA CONSIGNANDO:}

1. Acesso, a qualquer tempo, às informações sobre os procedimentos, riscos e benefícios relacionados à pesquisa, inclusive para dirimir eventuais dúvidas. O principal pesquisador é a Profa Dra. Vilma Leyton, que pode ser encontrado no endereço: Av. Dr. Arnaldo, 455 - Cerqueira César, São Paulo SP, tel: (11) 3061-8414. Se você tiver alguma consideração ou dúvida sobre a ética da pesquisa, entre em contato com o Comitê de Ética em Pesquisa (CEP) - Rua Ovídio Pires de Campos, 255 - $5^{\circ}$ andar - tel: (11) 3069-6442, ramais 16,17,18 ou 20, FAX: 3069-6442 ramal 26 - E-mail: cappesq@hcnet.usp.

2. Liberdade de retirar o seu consentimento a qualquer momento e de deixar de participar do estudo.

3. Salvaguarda da confidencialidade, sigilo e privacidade.

\section{CONSENTIMENTO PÓS-ESCLARECIDO}

Declaro que, após convenientemente esclarecido pelo pesquisador e ter entendido o que me foi explicado, consinto em participar do presente Protocolo de Pesquisa.

de de 2009. 
ANEXO 2 - Instrumento para coleta de dados

\begin{tabular}{|c|c|}
\hline \multicolumn{2}{|c|}{ IDENTIFICAÇÃO } \\
\hline Número de Controle Labo & ratorial: $\quad$ Entrevistador: \\
\hline \multicolumn{2}{|c|}{ Participante: (o) Aceitou participar ( ) Recusou participar, motivo: } \\
\hline Idade: & Sexo: Feminino ( ) Masculino ( ) \\
\hline \multicolumn{2}{|l|}{ Naturalidade (Cidade/UF): } \\
\hline \multicolumn{2}{|c|}{ Estado civil: Solteiro (ando Casado ( ) Viúvo ( ) Divorciado ( ) Amasiado ( ) } \\
\hline \multicolumn{2}{|c|}{ Etnia: Branca ( ) Negro ( ) Amarelo ( ) Pardo ( ) } \\
\hline $\begin{array}{l}\text { Escolaridade: Nunca estuc } \\
\qquad \begin{aligned} 1^{\circ} \text { a } 4^{\circ} \text { série } \\
5^{\circ} \text { a } 8^{\circ} \text { série } \\
\text { Curso técnic }\end{aligned}\end{array}$ & $\begin{array}{clll}\text { Escolaridade: Nunca estudou ( ) } & 2^{\circ} \text { grau } & \text { ( ) Outro: } \\
1^{\circ} \text { a } 4^{\circ} \text { série (N) } & 2^{\circ} \text { Grau Incompleto } & (\text { ( ) }\end{array}$ \\
\hline \multicolumn{2}{|c|}{ Tempo de Profissão: anos } \\
\hline \\
\hline \multicolumn{2}{|c|}{\begin{tabular}{l|l} 
Serviço: Contratado & Horas totais da viagem: \\
Modelo do caminhão: & Horas viajadas (até agora): \\
Ano do caminhão: & Dirige direto quantas horas \\
Percurso (Cidade/UF) Distância: __ & No de ocupantes no veículo: \\
Origem: & $\begin{array}{l}\mathrm{h} \\
\text { Destino: }\end{array}$ \\
\end{tabular}} \\
\hline Tempo de descanso: & 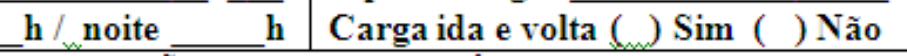 \\
\hline \multicolumn{2}{|r|}{ INFORMAC̣ÕES SOBRE A SAÚDE } \\
\hline $\begin{array}{l}\text { Pressão alta }(n) \text { Diab } \\
\text { DORES Lombar }( \\
\text { Atividade física Sim ( }) \\
\end{array}$ & $\begin{array}{l}\text { ete ( ) Estresse ( ) Outro ( ) Nenhum ( ) } \\
\text { Cervical ( ) Ombro ( ) Joelho ( ) Outro ( ) } \\
\text { Não ( ) Frequiência: vez/semana Tempo }\end{array}$ \\
\hline $\begin{array}{l}\text { Faz uso de bebidas } \\
\text { alcoólicas? }\end{array}$ & 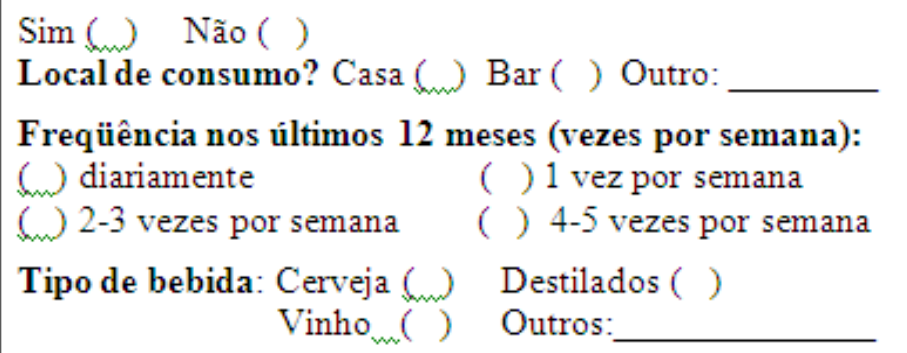 \\
\hline Fumante? & $\begin{array}{l}\text { Sim (n) Ex-fumante ( ) Não ( ) } \\
\text { Tempo de uso: } \\
\text { Quantidade de cigarros por dia: }\end{array}$ \\
\hline Usa rebite? & 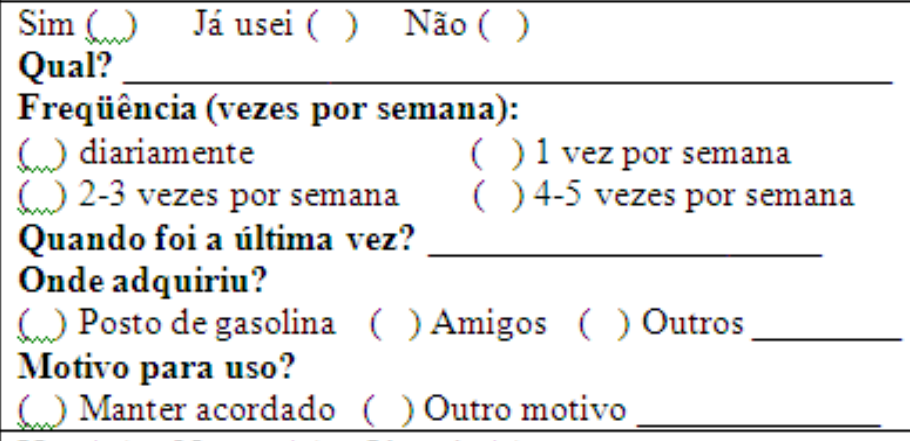 \\
\hline $\begin{array}{l}\text { Usa outro tipo de droga? } \\
\text { Maconha (. Crack ( ) } \\
\text { Cocaína ( ) Outras ( ) }\end{array}$ & $\begin{array}{l}\text { Uso ( } \text { ( ) Nunca ( ) Já usei ( ) } \\
\text { Freqüência (vezes por semana): } \\
\begin{array}{ll}\text { () diariamente } & \text { ( ) } 1 \text { vez por semana } \\
\text { (c) } 2-3 \text { vezes por semana } & \text { ( ) } 4-5 \text { vezes por semana } \\
\text { Quando foi a última vez? } & \end{array}\end{array}$ \\
\hline
\end{tabular}


ANEXO 3 - Aprovação CAPPesq

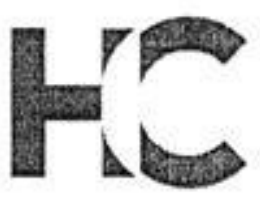

\section{APROVAÇÃO}

A Comissão de Ética para Análise de Projetos de Pesquisa CAPPesq da Diretoria Clínica do Hospital das Clínicas e da Faculdade de Medicina da Universidade de São Paulo, em sessão de 25/03/2009, APROVOU o Protocolo de Pesquisa $n^{\circ}$ 0093/09, intitulado: "USO DE SUBSTÂNCIAS PSICOATIVAS POR MOTORISTAS PROFISSIONAIS" apresentado pelo Departamento de MEDICINA LEGAL, ÉtICA MédICA E MEDICINA DO TRABALHO, inclusive 0 Termo de Consentimento Livre e Esclarecido.

Cabe ao pesquisador elaborar e apresentar à CAPPesq, os relatórios parciais e final sobre a pesquisa (Resolução do Conselho Nacional de Saúde $n^{\circ} 196$, de 10/10/1996, inciso IX.2, letra "c").

Pesquisador (es) Responsáveis: Profa. Dra. Vilma Leyton; Profa. Dra. Júlia D’Ándrea Greve; Keziah Cristina Barbosa Oliveira Pesquisador (es) Executantes: Daniele Mayumi Sinagawa; Carla Daniele de Godoy

CAPPesq, 27 de Março de 2009

Prof. Dr. Eduardo Massad Presidente da Comissäo de Ética para Análise de Projetos de Pesquisa

Comissáo de Ética para Análise de Projetos de Pesquisa do HCFMUSP e da FMUSP Diretoria Clinica do Hospital das Clinicas da Faculdade de Medicina da Universidade de Såo Paulo Rua Ovidio Pires de Campos,

225, $5^{\circ}$ andar - CEP 05403010 - Săo Paulo - SP Fone: 01130696442 Fax: 01130696492 e-mail: cappesq@hcnet.usp.br / secretariacappesq2@hcnet.usp.br 